\title{
"Funding Constraints and Market Illiquidity in the European Treasury Bond Market"
}

Sophie Moinas, Minh Nguyen and Giorgio Valentex 


\title{
Funding Constraints and Market Illiquidity in the European Treasury Bond Market*
}

\author{
Sophie Moinas $^{\dagger} \quad$ Minh Nguyen ${ }^{\ddagger} \quad$ Giorgio Valente ${ }^{\S}$ \\ May 22, 2017
}

\begin{abstract}
Theoretical studies show that shocks to funding constraints should affect and be affected by market illiquidity. However, little is known about the empirical magnitude of such responses because of the intrinsic endogeneity of illiquidity shocks. This paper adopts an identification technique based on the heteroskedasticity of illiquidity proxies to infer the reaction of one measure to shocks affecting the other. Using data for the European Treasury bond market, we find evidence that funding illiquidity shocks affect bond market illiquidity and of a weaker simultaneous feedback reverse. We also investigate the determinants of the magnitude of these effects in the cross-section of bonds and find that the responses of individual bonds' market illiquidity to funding illiquidity shocks increase with bond duration, with the credit risk of the issuer, and with haircuts.
\end{abstract}

JEL classification:

Keywords: Illquidity, Asset Pricing, Identification, Heteroskedasticity.

\footnotetext{
${ }^{*}$ We would like to thank Bruno Biais, Milo Bianchi, Markus Brunnermeier, Julio Crego, Rene Garcia, Nour Meddahi, Sebastien Pouget, Andreas Rapp, Enrique Santana, Marius Zoican, and seminar participants at the Finance seminar of Toulouse School of Economics, at Erasmus University, at the CORE (Louvain), and at ICEF (Moscow) for helpful comments. Part of this research was carried out while Giorgio Valente was Visiting Professor at the Einaudi Institute for Economics and Finance, whose hospitality is gratefully acknowledged, and while Sophie Moinas was appointed Judith C. and William G. Bollinger Visiting Professor at the Wharton School, University of Pennsylvania, and benefited from the support from the CNRS. Financial support from the Agence Nationale de la Recherche (ANR-16-CE26-0008-01, project PIMS) is gratefully acknowledged.

$\dagger$ Corresponding author: Toulouse School of Economics (University of Toulouse 1 Capitole, CRM and CEPR.) Toulouse, France. E-mail: sophie.moinas@ut-capitole.fr

${ }^{\ddagger}$ Newcastle University Business School, 5 Barrack Road, Newcastle upon Tyne, NE1 4SE; United Kingdom. Email: minh.nguyen@newcastle.ac.uk

${ }^{\S}$ Hong Kong Institute for Monetary Research, Hong Kong Monetary Authority, Central District, Hong Kong. E-mail: gvalente@hkma.gov.hk
} 


\section{Introduction}

Financial markets routinely experience a variety of frictions that hinder their efficient functioning by impacting price formation. These frictions are usually due to the organization of trading in a market, e.g. the design of a market structure or transaction costs, or to regulatory constraints, such as short-sale restrictions or market fragmentation. Several studies have recently exposed another source of friction: trading capital. As securities can be used as collaterals to relax borrowing constraints, there is a natural interplay between the ease with which traders can obtain funds (funding illiquidity, henceforth) and the ease with which an asset is traded (market illiquidity, henceforth)(see, Brunnermeier and Pedersen, 2009 and the references therein).

Despite the mounting theoretical and empirical evidence documenting the impact of both funding and market illiquidity on asset prices (see, among others, Vayanos and Wang, 2012; Foucault et al., 2013 and the references therein), little is known about the empirical relationship between the two dimensions of illiquidity. ${ }^{1}$ In particular, albeit the growing evidence that funding constraints have an impact on market illiquidity, the presence of a feedback effect of market illiquidity on funding illiquidity has not been documented. ${ }^{2}$ This paper aims at filling this gap and proposes an empirical investigation of the dynamic relationships between funding and market illiquidity measures in the context of the European Treasury bond market.

Our empirical investigation focuses on this market for several important reasons. First, the Treasury market is one of the largest and most liquid security market in the world, with a trading volume in 2015 of USD 6 trillion in the U.S., USD 5.9 trillion in Europe. ${ }^{3}$ Second, as Treasury securities are most often used as high-quality collateral in repo transactions, it is reasonable to conjecture that the illiquidity of the Treasury market would therefore be

\footnotetext{
${ }^{1}$ See for a recent policy address, Dudley (2016) and the references therein.

${ }^{2}$ For further details, see the selective review of the existing literature in Section 2.

${ }^{3}$ Source: SIFMA for the U.S., and MarketAxess for Europe.
} 
the one that potentially exhibits the largest feedback effect to funding illiquidity shocks, in the spirit of Brunnermeier and Pedersen's (2009) original argument. For instance, Krishnamurthy, Nagel, and Orlov (2014) find that the collaterals backing the repos in the U.S. prior to the crisis were largely composed of government securities rather than riskier private sector assets. Third, trading of European Treasury securities falls under the jurisdiction of the European Central Bank (ECB) and it is regulated by the same entity, the European Commission. European Treasury bonds are traded in a large supranational secondary market whose liquidity conditions respond to aggregate funding illiquidity shocks, and they are denominated in the same currency. The ECB also supervises the financial institutions who trade in the European market. At the same time, these securities are issued by countries with different sovereign risk (and different ratings), which generates heterogeneity in the sample. In particular, notwithstanding the introduction of the Euro, bond markets in Europe are probably less homogenous than in the U.S., with multiple issuers, and country-specific tax considerations. Finally, the European repo market widely differs from the U.S. repo market along various dimensions. This in turn suggests that counterparty risk may play a different role compared to the evidence reported in previous studies. ${ }^{4}$

In motivating our empirical investigation we start from noting that the analysis of the dynamic relationships between funding and market illiquidity measures suffers from various shortcomings. One key issue that emerges from the majority of existing studies is that the investigation of the impact of funding and/or market illiquidity on asset prices is usually carried out by using empirical proxies that are recorded at the low frequency (usually monthly or even annual). This data limitation makes any statement regarding potential causation

\footnotetext{
${ }^{4}$ See Mancini, Ranaldo and Wrampelmeyer (2015) for a discussion on differences between the U.S. and the European repos markets, and their potential impact on the resiliency of the repo market. In particular, they point out differences with regards to the proportion of triparty repo transactions and the absence of an "unwind" mechanism. They note that in Europe, "repos with government bonds and other relatively safe securities as collateral are predominantly CCP based and traded via anonymous electronic platforms," and they document an increase in the market share of CCP-based repo transactions from $42 \%$ to $71 \%$ between 2009 and 2013.
} 
links between the two dimensions of illiquidity dubious because of their intrinsic endogeneity and the fact that both market and funding illiquidity may react to the same exogenous variables. $^{5}$

In order to circumvent this issue, we adopt an identification technique based on the heteroskedasticity of the illiquidity measures that has been successfully used in other contexts (see, Rigobon, 2003, Rigobon and Sack, 2003; 2004 and the references therein). More specifically, we assume that changes in the variance of funding illiquidity shocks relative to market illiquidity shocks affect the covariance between market and funding illiquidity in a way that depends on the responsiveness of market illiquidity to and from funding illiquidity. Thus, we exploit the existence of various volatility regimes in both funding and market illiquidity to estimate the impact of funding (market) illiquidity shocks to market (funding) illiquidity shocks based on the observed shifts in that covariance matrix. ${ }^{6}$

We carry out our empirical investigation using a dataset containing all European Treasury bonds that are traded on the Mercato Telematico dei Titoli di Stato (MTS henceforth) platforms over the period October 1st, 2004 - February 28th, 2011. MTS is the most important electronic platform for euro-denominated government bonds and it consists of number of domestic markets (i.e., local MTS) and a centralized European marketplace (i.e., EuroMTS). Persaud (2006) reports that the MTS platforms, around the sample period used in the empirical investigation, jointly cover just over $70 \%$ of the overall electronic trading of European government bonds (see also, Gyntelberg et al., 2013 and the references therein). ${ }^{7}$

\footnotetext{
${ }^{5}$ It is also worthwhile mentioning that both market and funding illiquidity are, by their very nature, difficult to define and even more difficult to estimate. This difficulty is reflected in the multitude of empirical proxies proposed in a vast number of studies and the fact that any proxy may be a poor approximation of the same facet of illiquidity as they all contain a common or systematic component which correlates across empirical proxies that is important for the pricing of illiquidity risk (see Goyenko et al., 2009 and Korajczyk and Sadka, 2008 and the references therein). We will explore this issue in detail in Section 4.

${ }^{6}$ In our empirical estimation, we select three volatility levels based on the volatility of vStoxx index returns, i.e., an index of the implied volatility in European stocks, and we document the behaviour of funding and market liquidity in each of these three regimes. Some robustness checks relative to this choice are carried out in Section 5.

${ }^{7}$ In our empirical investigation we use the consolidate set of quotes and trades occurring on both local MTS and EuroMTS.
} 
We find a host of interesting results: First, contemporaneous shocks to funding illiquidity are found to significantly affect the market illiquidity of the European Treasury market, also after controlling for endogeneity. A one standard deviation shock to funding illiquidity, that is a relaxation of funding constraints, generates a contemporaneous improvement of 0.15 standard deviation of market liquidity across Treasury bond markets.

Second, contemporaneous shocks to market illiquidity also significantly affect funding conditions: we find that one standard deviation shock to market illiquidity across European Treasury markets generates a increment of 0.08 standard deviation of funding illiquidity, that is a tightening of funding constraints. We thus document the presence of a positive feedback effect of the bond market illiquidity on funding illiquidity. These effects are sizable and economically significant. ${ }^{8}$ This result is crucial for two reasons. First, it shows the presence of a feedback effect from market illiquidity to funding illiquidity, which has been theoretically formalized by Brunnermeier and Pedersen (2009). Second, it shed further light on the direction of this impact. Brunnermeier and Pedersen (2009)'s model is indeed characterized by multiple equilibria; thus the market illiquidity may yield to an increment or a reduction of margins, thus on funding contraints, depending on the equilibrium achieved. Our results therefore suggest that market illiquidity and funding illiquidity are mutually reinforcing, leading to illiquidity spirals.

Third, after estimating the responses for individual bonds in our sample, we find that the coefficients measuring the impact of funding illiquidity shocks on each bond's market illiquidity are on average positive, but with a different size across bonds. This suggests, in light of Brunnermeier and Pedersen (2009), that margins are on average destabilizing, or that the equilibrium is characterized by illiquidity spiral effects. We then explain the

\footnotetext{
${ }^{8}$ For example, a one standard deviation decrease in the Euribor-OIS spread (a proxy for funding illiquidity), generates a contemporaneous decrease of $0.35 \mathrm{bp}$ of the effective spread in European Treasury bonds (a proxy for market illiquidity), that is, an improvement of $9 \%$ of the average effective spread. Conversely, a one standard deviation decrease in the effective spread generates a contemporaneous decrease of $0.32 \mathrm{bp}$ of the Euribor-OIS, that is, an improvement of $5.2 \%$ of the average Euribor-OIS spread.
} 
heterogeneity of parameter estimates by running a cross-sectional regression with the aim of disentangling the determinants of the individual bonds' illiquidity responses. The results of this final exercise show that the responses of individual bonds' market illiquidity to funding illiquidity shocks is higher for long-term bonds, which are more capital intensive than shortterm bonds. By contrast, the responses of funding illiquidity to individual bonds' market illiquidity shocks are lower for bonds with longer durations or higher credit risk that are used less frequently as collaterals in repo transactions.

The rest of the paper is organized as follows. Section 2 discusses the literature. Section 3 describes the empirical framework and introduces the measures used to proxy for market and funding illiquidity. Section 4 describes the data used in this study, presents preliminary summary statistics and reports the results of the main estimations. Section 5 discusses the results of various robustness checks. A final section concludes.

\section{$2 \quad$ Related Literature}

The theoretical literature dealing with the interplay between funding conditions and trading in security markets is vast and rich. Brunnermeier and Pedersen (2009) are among the first to elaborate on the relationship between funding illiquidity and market illiquidity. When a trader buys a security she can use it as collateral and then borrow a fraction of its value against it. The difference between the security price and its collateral value must be financed by traders' own capital. When this realistic feature of trading is taken into account, illiquidity assumes a dual perspective: They show that the two notions of funding and market illiquidity are mutually reinforcing, and in particular that market illiquidity would also impact funding illiquidity. Indeed, endogenous variation of margin constraints by financiers in equilibrium may result in amplifying effects: under certain circumstances, margins can be destabilizing leading to cases of perverse illiquidity spirals.

The idea that market illiquidity is influenced by the risk-bearing capacity of market 
participants, which in turn is related to the amount of capital allocated to this activity, is however not new. When investors need to trade and need immediacy, their orders would typically be matched with those of two types of financial institutions: market makers, who temporarily absorb imbalance by holding a possibly short term position in their inventory; or other intermediaries, like mutual or hedge funds, who may either be ready to absorb imbalance for a longer period, or to arbitrage prices. Various models suggest that these participants' wealth may be used directly to buy financial assets or as collateral to borrow cash or securities and engage into these activities.

This is for instance the case in inventory models of market making (see Demsetz, 1968, Stoll, 1978, or Ho and Stoll, 1981) that have been formalized by Weill (2007), who analyzes the link between the cost faced by market makers to raise capital and liquidity provision. ${ }^{9}$ More recently, D'Souza and Lai (2006) and Lescourret and Robert (2011) discuss how funding capital may impact the behavior of dealers and thus market illiquidity in the context of bank consolidation or order preferencing.

More generally, capital is required to arbitrage markets. This is especially important when one needs to hold positions for some time or across large baskets of securities. Constraints on the borrowing capacity of other financial institutions who typically absorb demand/supply pressure, like mutual funds or hedge funds, may indeed create limits to arbitrage, as phrased by Shleifer and Vishny (1997). In particular, they show that investors' outflows from managed funds can amplify financial assets' negative 'sentiment' shocks. The literature has shed light on other mechanisms, like endogenous margin constraints (Gromb and Vayanos, 2002, Geanakoplos, 2003) or the role of repos (Huh and Infante, 2016), and analyzed their impact in various context, i.e., across markets (Kyle and Xiong, 2001) or during a financial crisis

\footnotetext{
${ }^{9}$ Demsetz (1968) for instance writes that "this role of the specialist involves judgment, investment, and risk taking", while Stoll (1978) notes that "dealer inventory positions acquired in the process of providing immediacy are financed solely at the risk free rate of interest. (...) The dealer's personal wealth (his investment account) and the position in the trading account serves as collateral for the borrowing of cash or of shares."
} 
(He and Krishnamurthy, 2012 and 2013).

The empirical evidence of the effects of funding constraints on market trading is, however, usually indirect. Some studies explore the prediction that funding constraints would affect all the operations of traders, creating a systematic source of variation in illiquidity across financial assets. Coughenour and Saad (2004), Comerton-Forde et al. (2010), Hameed, Kang, and Viswanathan (2010), or Jensen and Moorman (2010) document links between factors influencing market makers' capital constraints, such as its portfolio of stocks, losses, negative returns, or monetary conditions; and market illiquidity. Analyzing reversal strategies, Nagel (2012) finds evidence of withdrawal of liquidity supply, and an associated increase in the expected returns from liquidity provision during times of financial market turmoil, consistent with theories of liquidity provision by financially constrained intermediaries. The results of Bessembinder et al. (2016) suggest that post-crisis regulations focused on banking may have unintended consequences on bond market illiquidity, by comparing the participation between bank-affiliated dealers and non-bank dealers before and after post-crisis changes in regulation.

A few papers propose a different approach and investigate the impact of funding constraints on the persistence of limits to arbitrage, as evidenced for instance by deviations from Covered Interest Parity (CIP) (see, among others, Coffey et al., 2009, Mancini Griffoli and Ranaldo, 2010) or noise (or predictability) in the cross section of bond returns, in particular across maturities (see for instance Adrian, Etula, and Muir, 2014, Garcia and Fontaine, 2012, Hu et al., 2013, or Musto et al., 2015.)

The use of non-conventional policies (such as quantitative easing) by central banks in the aftermath of the 2008-2009 financial crisis has also enabled to assess the impact of the relaxation of funding constraints on asset prices. The impact of these interventions is however debated. ${ }^{10}$ Trebbi and Xiao (2015) find no evidence of structural deterioration of liquidity

\footnotetext{
${ }^{10}$ For example, some argue that the relaxation of funding constraints might have occurred at the expenses of market participants, as some have been evicted from the relevant markets.
} 
following these interventions in the U.S. corporate bond market. Deuskar and Johnson (2016) control for links between market and funding illiquidity using the Identification through Heteroskedasticity approach, and find that bond market illiquidity of the 10-year Indian government bond is reduced with greater funding liquidity provision by the central bank (RBI). Besides, Pelizzon, Subrahmanyam, Tomio, and Uno (2016) find that the Long-Term Refinancing Operations (LTRO) of the European Central Bank weakened the sensitivity of market makers' liquidity provision to credit risk, highlighting the importance of funding illiquidity measures as determinants of market illiquidity of the European sovereign bond market.

Finally, other studies directly exploit differences on margin requirements across similar assets, variations in margin policies, or shocks to the latter, in order to assess the impact of variations of funding constraints on market illiquidity. Aragon and Strahan (2012) use Lehman bankruptcy as instrument and find that stocks held by Lehman-connected funds (that is, funds that used Lehman as prime broker) experienced greater increment in market illiquidity following the bankruptcy than other stocks. Miglietta, Picillo, and Pietrunti (2015) document a significant and positive effect of variations of CCPs' initial margins on the Italian MTS GC repo rates. Hedegaard (2014) finds that following a margin increase, the price impact of trading increases for both the affected contract and for the remaining contracts in the market, documenting funding illiquidity spillovers. Kahramand and Tookes (2016) employ a regression discontinuity design based on the threshold rules that determine a stock's margin trading eligibility in India to identify a causal relationship between traders' ability to borrow and a stock's market illiquidity. They find that illiquidity is lower when stocks become eligible for margin trading. Using a quasi-experiment, Jylh'a (2015) shows that the SEC-approved changes in the computation of the margin requirements for portfolios of options traded in the U.S., that led to a decrease in the capital required to fund index option 
trading, significantly reduced market illiquidity relative to that of unaffected securities. ${ }^{11}$

Consistently with most studies in this literature, we find evidence of a positive and significant impact of funding constraints on market illiquidity. More importantly, our econometric model also enables us to explore the reverse causality link. Our main contribution is to document the presence of a feedback effect of market illiquidity on funding illiquidity that has been theoretically highlighted by Brunnermeier and Pedersen (2009), to find out that this effect is positive, and to analyze its determinants. The closest paper to ours, Boudt, Paulus, and Rosenthal (2013), investigate a similar question, using a different approach than ours to address the endogeneity issue between market and funding illiquidity meaasures. They rely on two natural instruments which are supposed to isolate the exogenous variation in equity market illiquidity, namely a variable capturing the trend in average time between trades, and the change in yields for short-term AAA-rated corporate bonds versus change in Treasury bill rates. They find evidence of two regimes, one in which illiquidity spirals are stabilizing and the other in which they are destabilizing, over the period July 2006 May 2011. ${ }^{12}$ By contrast, we rely on an econometric approach, namely the Identification through Heteroskedasticity, that explicitly tackles the endogeneity issue between both aspects of illiquidity, and we use the heterogeneity in government bonds characteristics across European countries to investigate the determinants of the responses of market illiquidity shocks on funding illiquidity. Our results are in line with some of their findings. However, we differentiate from them in that we quantify empirically and economically the responses of market illiquidity to funding illiquidity and we report evidence of a positive and significant feedback effect of market illiquidity on funding illiquidity. Furthermore, we explain how

\footnotetext{
${ }^{11}$ Garleanu and Pedersen (2011) and Kitsul et al. (2016) further document that the funding illiquidity risk is priced. The former show that securities with (nearly) identical cash flows but different margin requirements can be traded at different prices. The latter shows that funding illiquidity risk is priced in the cross-section of excess returns on agency mortgage-backed securities (MBS).

${ }^{12}$ Note that Dick-Nielsen, Gyntelberg, and Lund (2013) use Granger causality tests from funding liquidity to market liquidity. They find that Euro spreads, their measure of funding liquidity, drive the changes in the market liquidity on the Danish bond market on the period spanning from November 2007 to December 2011.
} 
bonds' characteristics influence the magnitude of the effects.

\section{$3 \quad$ Empirical methodology}

In this section, we first introduce the main empirical proxies for market and funding illiquidity used in the empirical investigation. Then we discuss the empirical framework adopted to identify the relationships between funding and market illiquidity based on the heteroskedasticity of illiquidity measures in the spirit of Rigobon (2003) and Rigobon and Sack (2003).

It is worthwhile noting that the existing literature uses various measures to capture different aspects of market and funding illiquidity across markets, that we present below. We acknowledge that the various measures only proxy illiquidity along one dimension and cannot perfectly reflect its multifaceted nature. Nonetheless, in our empirical investigation, we report and discuss our baseline results both in terms of single representative measures of market and funding illiquidity and, in the spirit of Korajczyk and Sadka (2008), the first principal components computed across the pool of all empirical proxies discussed in this Section.

\subsection{Market illiquidity measures}

Since Amihud and Mendelson (1986), the bid-ask spread remains the most popular illiquidity measure. For each bond in our sample, we use intraday quote data to compute quoted bidask spreads on daily basis. In particular, we compute for each bond $j$ the difference between ask and bid quotes divided by the spread midpoint. We then take the average over all best quote revisions for day $d$ as follows:

$$
B A S_{d}^{j}=\frac{1}{N Q_{d}^{j}} \sum_{i=1}^{N Q_{d}^{j}} \frac{\left(A s k_{i}^{j}-B i d_{i}^{j}\right)}{\left(A s k_{i}^{j}+B i d_{i}^{j}\right) / 2},
$$

where $B i d_{i}^{j}$ and $A s k_{i}^{j}$ are the $i$-th bid and ask quote prices, $N Q_{d}^{j}$ is the total number of quote revisions for day $d$. To avoid outliers we exclude quotes with the bid-ask spread greater than 
100 basis points and those outside the trading hours (8:15 am - 5:30pm Central European Time). We then average daily measures at the weekly level as follows:

$$
B A S_{t}^{j}=\frac{1}{D(t)} \sum_{d=1}^{D(t)} B A S_{d}^{j}
$$

where $D(t)$ is the number of trading days in week $t$.

Second, Fleming (2003) suggests that the bid-ask spread is a valid measure in the U.S. government bond markets because it consistently captures the variations in market illiquidity. However, as the bid-ask spread is computed from the intraday data, it might be affected by the deterministic time-of-day effects described by Admati and Pfleiderer (1988). Furthermore, bid-ask spreads may not be a good measure of transaction costs if traders strategically trade when spreads are low. In order to take this issue into account, we follow Lee (1993) and compute the daily average effective spread of bond $j$, which measures the difference between the transaction price and the mid-quote price prevailing at the time of the trade:

$$
E B A S_{d}^{j}=\frac{1}{N T_{d}^{j}} \sum_{\tau=1}^{N T_{d}^{j}} \frac{\left(\operatorname{TPrice}_{\tau}^{j}-\frac{\left(A s k_{\tau}^{j}+B i d_{\tau}^{j}\right)}{2}\right)}{\frac{\left(A s k_{\tau}^{j}+B i d_{\tau}^{j}\right)}{2}} \times d i r_{\tau}
$$

where $B i d_{\tau}^{j}$ and $A s k_{\tau}^{j}$ are the best ask quote prices prevailing before the $\tau$ th trade, TPrice ${ }_{\tau}^{j}$ is the execution price, $N T_{d}^{j}$ is the total number of trades for day $d$, and $d i r_{\tau}$ the direction of the trade that takes value 1 if the trade is initiated by a buy order, and -1 otherwise. Using the same notations as for the bid-ask spread, we similarly compute the weekly average effective spread as:

$$
E B A S_{t}^{j}=\frac{1}{D(t)} \sum_{d=1}^{D(t)} E B A S_{d}^{j}
$$

Effective spreads abstract from intraday patterns since they are computed using the bidask spreads prevailing at the time when actual transactions occur. Besides, they successfully capture the (indirect) cost of an aggressive transaction, whatever its size, which indirectly accounts for market depth. We therefore use this variable as our proxy for market illiquidity 
when focusing on single measures of market illiquidity.

Third, while the spread measures matter for brokers and investors, they may not perfectly reflect the capacity of the market to absorb orders without moving prices, therefore they may not be the most appropriate measures to capture the market illiquidity risk faced by market participants. Researchers and the industry therefore use a measure of the "price impact" of transactions, in the spirit of Kyle's lambda. ${ }^{13}$ A market is considered less liquid if a small order can cause a large adverse impact on prices. Following Brennan and Subrahmanayam (1996), we measure the price impacts of a trade as in Hasbrouck (1991) using the following Vector Autoregressive (VAR) for each bond $j$ on a weekly basis:

$$
\begin{aligned}
q r_{\tau} & =\sum_{i=1}^{m} a_{t, i}^{j} q r_{\tau-i}+b_{t, 0}^{j} x_{\tau}+\sum_{i=1}^{m} b_{t, i}^{j} x_{\tau-i}+v_{1 \tau}, \\
x_{\tau} & =\sum_{i=1}^{m} c_{t, i}^{j} q r_{\tau-i}+\sum_{i=1}^{m} d_{t, i}^{j} x_{\tau-i}+v_{2 \tau},
\end{aligned}
$$

where $q r_{\tau}$ is the change in mid-quote prices due to a trade at date $\tau$ and $x_{\tau}$ is the net aggregate buy and sell volume for all trades executed between transaction time $\tau-1$ and time $\tau . v_{1 \tau}$ is the innovation in quote change, $v_{2 \tau}$ is the unexpected component of the order flow, $m$ is the order lags in the autoregression while $a_{t}^{j}$ 's, $b_{t}^{j}$, s, $c_{t}^{j}$, s and $d_{t}^{j}$ 's are the coefficients estimated for bond $j$ in week $t$. The coefficient $b_{0}^{j}$ measures the immediate price response to the trade and is used as our price impact measure. ${ }^{14}$

Third, another conventional empirical proxy for market illiquidity is the $I L L I Q$ measure developed by Amihud (2002). This measure is defined as the average of the daily ratio of

\footnotetext{
${ }^{13}$ This practice has become common in the industry. This is in particular due to data availability, but also to the rise of algorithmic trading in the 2000s which has induced brokers to strategically split orders across time with the objective to soften the "price impact" of their trades. The SEC and the most recent literature similarly suggest to use the "price impact" of transactions as an alternative measure of illiquidity (see for instance Brogaard, Hendershott, and Riordan, 2014.) For instance, in the "Liquidity Management Rules For Mutual Funds And ETFs" released by the SEC on Sept 22nd, 2015, the SEC suggests a "classification of the liquidity of fund portfolio assets based on the amount of time an asset would be able to be converted to cash without a market impact".

${ }^{14}$ In our empirical exercise, we find that three is the appropriate order of lags $m$ in the model.
} 
bond $j$ 's absolute returns to the total trading volume over a period of $D$ days in week $t$ :

$$
I L L I Q_{t}^{j}=\frac{1}{D} \sum_{d=1}^{D} \frac{\left|r_{d}^{j}\right|}{V_{d}^{j}},
$$

where $r_{d}^{j}$ is the daily return and $V_{d}^{j}$ is the total trading volume on day $d$ in week $t$. Similarly to Hasbrouck (1991)'s $b_{0}$ coefficient, ILLIQ measure captures the average price impact over $D$ trading days. A bond is less liquid or, put differently, ILLIQ is high if a small trading volume can induce a large price change. The ILLIQ measure uses more aggregated information than the three measures defined above and may be less affected by microstructure noise.

\subsection{Funding illiquidity measures}

While funding illiquidity is an increasingly relevant concept that extends and complements the one of market illiquidity, the literature has still not converged on a unambiguous way to measure it. We consider four alternative variables to capture funding illiquidity conditions in the European Treasury bond market. ${ }^{15}$

First, our main proxy for funding illiquidity is the spread between the Euro interbank offered rate (Euribor) and the overnight index swap rate (OIS) both with the maturity of one week. The Euribor-OIS spread has been discussed extensively in the literature as a proxy for funding liquidity (see, inter alia, Taylor and Williams, 2009; Baba and Packer, 2009 and the references therein). Offered rates are interest rates over unsecured deposits that a bank is willing to offer to another bank over a given maturity term. They can be high because of larger default/counterparty risk or because of poor interbank liquidity conditions. An overnight index swap is an agreement between two counterparts to pay the difference between a fixed interest rate and an average of overnight interest rates, i.e. the EONIA in the context of the euro area. By contrast to Euribor, OIS reflects little default or liquidity risk as the contract does not involve the exchange of principal while only net interest

\footnotetext{
${ }^{15}$ All measures discussed in this section are computed at the weekly frequency.
} 
obligations are settled at maturity. The Euribor-OIS spread reflects the state of credit and funding conditions in the interbank market. We consider variations in Euribor-OIS spread as originating from liquidity conditions in light of the recent findings suggesting that liquidity conditions, not credit credit conditions, are the main drivers of short-term interbank spreads (Schwartz, 2016).

A second measure often used to proxy for funding liquidity relies on repo rates (see for instance Dunne, Flemming and Zholos, 2013). We consider the spread between the Euribor and the Eurepo. Eurepo is the rate at which a prime bank offers funds in euro to another prime bank against an accepted asset of suitable quality i.e. Eurepo General Collateral serving as the collateral in the transaction. ${ }^{16}$ The Euribor spread over the Eurepo captures the state of funding conditions for secured money market transactions in the euro area. As indicated by Hördahl and King (2008), a higher repo spread is associated with higher risk aversion, a higher preference for cash as well as a greater uncertainty in the collateral value. ${ }^{17}$ This measure may therefore complement the Euribor-OIS spread by accounting for changes in funding conditions that are not captured by interbank interest rate spreads.

A third potential measure of funding illiquidity is the difference between the average main refinancing operation (MRO) rate and the OIS rate. MRO remains one of the most important tools used by the European Central Bank to manage liquidity and implement monetary policies in the euro area (ECB, 2011). MRO involves weekly auctions at which banks borrow money with one week maturity, i.e. allotted liquidity, from the ECB secured against a collateral accepted by the central bank. Using proprietary data on individual demands by financial institutions during the ECB auctions between June 2005 and October

\footnotetext{
${ }^{16}$ According to Mancini et al. (2015), the repo market in the euro area is growing rapidly and is of a similar size as the U.S. market.

${ }^{17}$ Although European Money Markets Institute decided to discontinue to publish the Eurepo index from Jan 2015, an emerging benchmark for repo market in the euro area is RepoFunds Rate (see http://www.repofundsrate.com). This rate captures the repo transactions executed on the BrokerTec and MTS trading platform. However, due to the limited availability of historical data of RepoFunds Rate, we use Eurepo rate in our study.
} 
2008, Drehmann and Nikolaou (2012) show that an increase in auction rates in MROs is associated with higher funding constraints faced by banks and a reduction in market liquidity across stock, bond and money markets in the euro area.

Finally, the last funding illiquidity measure we considered is not related to market interest rate spreads but has been found significant in explaining funding conditions in the US Treasury market, namely the noise measure introduced by $\mathrm{Hu}$ et al. (2013). This measure is based on the assumption that the availability of capital allows traders to engage in arbitrage activities and help smooth out yield differentials around an equilibrium yield curve. When funding constraints bind and arbitrage capital is curtailed, bond yields become more disconnected from each other. That, as a result, leads to bonds that are priced away from their equilibrium values. Put differently, when funding conditions deteriorate, bond prices become more noisy. According to Hu et al. (2013), this measure of noise can be empirically computed as the root-mean-squared-error of market yields and a given equilibrium model yields, across all bonds:

$$
\text { Noise }_{t}=\sqrt{\frac{1}{N_{t}} \sum_{i=1}^{N_{t}}\left(y_{t}^{i}-y_{b, t}^{i}\right)^{2}},
$$

where $N_{t}$ is the number of bonds, $y_{t}^{j}$ is the market yield of bond $j$ and $y_{b, t}^{j}$ is the implied model bond yield at time $t$. In our empirical exercise, we first compute equilibrium yield curves by means of the Nelson and Siegel (1987) methodology using bonds with maturity ranging from 1 year to 10 years for France, Germany, Italy and Spain. We then compute a noise measure for each country on weekly basis and obtain an aggregate noise measure as the first principal component computed across the four countries. ${ }^{18,19}$

\footnotetext{
${ }^{18} \mathrm{As} \mathrm{Hu}$ et al. (2013) show that their main results are not specific to a particular curve-fitting method employed, we chose to adopt a Nelson and Siegel (1987) methodology.

${ }^{19}$ In a previous version of the paper, we had included Fontaine and Garcia (2012)'s measure that is based on the interest rate differential between on-the-run / off-the-run bonds with similar maturities. However, since most Treasury agencies in Europe use re-openings to avoid off-the-run securities, this measure may not be a proxy for funding liquidity in Europe. Results are however very similar when including it, and are available upon request.
} 


\subsection{Identification through heteroskedasticity}

In this section we discuss the framework adopted to investigate the relationship between funding and market illiquidity, acknowledging that their dynamics are endogenously determined. Theories of financial intermediation suggest a direct dual causality between the two dimensions of illiquidity. Nonetheless, the empirical identification of this relationship is not a trivial task. In fact, as illiquidity conditions are initially observed at different and potentially low frequencies, it difficult to empirically disentangle whether any shock to one of the two dimensions of illiquidity causes changes in the other or whether both dimensions of illiquidity are endogenously determined.

We do not take a specific stand on the direction of causality and investigate the dynamic interaction between market and funding illiquidity by adopting the methodology proposed in Rigobon (2003) and Rigobon and Sack (2003). More specifically, we assume that market and funding illiquidity follow the system of simultaneous equations:

$$
\begin{aligned}
m_{t} & =\beta f_{t}+\epsilon_{t} \\
f_{t} & =\alpha m_{t}+\eta_{t},
\end{aligned}
$$

where $m_{t}$ and $f_{t}$ are measures of aggregate market and funding illiquidity, respectively; $\epsilon_{t}$ and $\eta_{t}$ are the structural shocks with zero mean and variances $\sigma_{\epsilon}^{2}$ and $\sigma_{\eta}^{2}$, and $\beta$ and $\alpha$ are the key parameters of interest in the model. We also assume that the shocks affecting market and funding illiquidity in the model are uncorrelated, i.e. $E\left(\epsilon_{t} \eta_{t}\right)=0 .{ }^{20}$ Albeit very stylized, the two equations have a straightforward interpretation in light of Brunnermeier and Pedersen's (2009) theoretical framework. In fact, the first equation of the system captures the essence of the finding whereby any asset's market illiquidity is a function of common funding

\footnotetext{
${ }^{20}$ For the sake of exposition, we use a simple model where there are no exogenous variables affecting the dynamics of both dimensions of liquidity. However, this assumption is relaxed later. See Appendix 2 for further details.
} 
illiquidity. $^{21}$ The second equation is less rooted into this specific theoretical framework. However, it can be viewed as a simplified counterpart of the finding for which the shadow cost of capital, used as proxy for a common funding illiquidity measure, is a function of market illiquidity and endogenous margins. ${ }^{22}$

Several studies have recorded that the parameter $\beta$ of similar relationships is different from zero and usually statistically significant at conventional level. A couple of studies have noted that $\alpha$ was also different from zero. However, existing studies did not explicitly take into account the endogeneity of the liquidity variables. In fact, the system above cannot be estimated, unless further information is incorporated. This is because an identification problem occurs, as the covariance matrix of the reduced form of the above system of equation provides only three moments (variance of funding and market liquidity and the covariance of their shocks), but four parameters have to be estimated.

Rigobon (2003) suggests that if the variance of the structural shocks is subject to regimes, then the identification problem can be solved. ${ }^{23}$ If we assume for simplicity that the variance of both structural shocks $\epsilon$ and $\eta$ is subject to only two regimes (i.e. variances of both shocks are either high or low) and, most importantly, the structural parameters $\alpha$ and $\beta$ are stable across regimes then the covariance matrix of the reduced form, as it is regime-specific, will provide six moments (three per regime) for six parameters to be estimated (namely $\alpha, \beta$, and four variances), which solves the identification problem.

It is instructive to note that this identification procedure can be intuitively explained. In fact, the estimation of the two structural parameters assumes that both variances of market and funding illiquidity shocks change over time. For example, consider a sudden increase in the variance of funding illiquidity shocks. If an econometrician observes a contemporaneous

\footnotetext{
${ }^{21}$ See Proposition 1 in Brunnermeier and Pedersen (2009, p. 2211).

${ }^{22}$ See equation (14) and Propositions 2,3 in Brunnermeier and Pedersen (2009).

${ }^{23}$ The identification through heteroskedasticity is not the only solution to the identification problem highlighted above. In fact, the parameter $\alpha$ and $\beta$ can still be estimated by 1 ) imposing zero or sign restrictions on the parameters, 2) assuming long-run constraints, or 3) imposing constraints on variances. See Rigobon (2003) and the references therein.
} 
increase in market illiquidity, given the assumption that the covariance between funding and market illiquidity shocks is zero, the change in market illiquidity is exclusively due, in light of the above system of equations, to the effect of funding illiquidity on market illiquidity (i.e. $\beta f_{t}$ ). By observing the changes in market and funding illiquidity in this specific volatility regime, then it is possible to back out the value of the parameter $\beta$. A similar narrative applies for the estimation of the other parameter $\alpha$.

More formally, under the assumption of two regimes, the regime-specific covariance matrix of the reduced form can be written as follows:

$$
\begin{aligned}
\Omega_{s} & =\frac{1}{(1-\alpha \beta)^{2}}\left[\begin{array}{cc}
\beta^{2} \sigma_{\eta, s}^{2}+\sigma_{\epsilon, s}^{2} & \beta^{2} \sigma_{\eta, s}^{2}+\alpha \sigma_{\epsilon, s}^{2} \\
\cdot & \sigma_{\eta, s}^{2}+\alpha^{2} \sigma_{\epsilon,}^{2}
\end{array}\right] \\
& =\left[\begin{array}{cc}
\omega_{11, s} & \omega_{12, s} \\
\cdot & \omega_{22, s}
\end{array}\right],
\end{aligned}
$$

where $s \in\{1,2\}$. Solving for the variances in the regime-dependent reduced form, leads to the definition of the estimates of the parameters $\beta$ and $\alpha$ (see Appendix 1 for more details). The $\beta$ parameter is estimated as:

$$
\beta=\frac{\omega_{12, s}-\alpha \omega_{11, s}}{\omega_{22, s}-\alpha \omega_{12, s}}
$$

and the parameter $\alpha$ solves the following quadratic equation:

$$
\left[\omega_{11,1} \omega_{12,2}-\omega_{12,1} \omega_{11,2}\right] \alpha^{2}-\left[\omega_{11,1} \omega_{22,2}-\omega_{22,1} \omega_{11,2}\right] \alpha+\left[\omega_{12,1} \omega_{22,2}-\omega_{22,1} \omega_{12,2}\right]=0 .
$$

The identification through heteroskedasticity fails if the two covariance matrices are proportional, i.e. the relative variances are constant across regimes. The empirical analysis in Section 4 includes exogenous variables, and the model with latent variables is estimated as a robustness check in Section 5. ${ }^{24}$

\footnotetext{
${ }^{24}$ See Appendix 2 for further details.
} 


\section{Empirical analysis}

In this section, we first present the data and the descriptive statistics of the various illiquidity measures. Prior to estimating the reduced-form model and adopt the identification methodology discussed in Section 3.3, we formally test that time series of the variables of interest are indeed subject to heteroskedasticity. We finally explore the dynamic relationship between funding and market liquidity using this framework.

\subsection{European government bond markets and the trading environ- ment}

Our study examines bonds issued by the governments of the ten Euro area countries including Austria, Belgium, Germany, Finland, France, Greece, Italy, the Netherlands, Portugal and Spain, with maturities between one year and thirty years. ${ }^{25}$ Similarly to Beber et al. (2009), we only select fixed-rate and zero coupon bonds and exclude those with special fixed-income features such as floating rate coupons, inflation-linked or inflation-indexed indexed bonds, securities traded prior to issue (when issued). ${ }^{26}$

During the period investigated, the European Treasury bond markets are mostly dealer markets with investment banks committing their own capital and providing liquidity to facilitate trading; around $50 \%$ of trading in government bonds was conducted over the telephone. ${ }^{27}$ The European government bond market is thus reputed transparent ex ante with dealers advertising the prices at which they are prepared to trade, but not ex post. ${ }^{28}$ In particular, closing prices are available through data vendors but there is little information

\footnotetext{
${ }^{25}$ The Euro Bond Market Study of the European Central Bank published in December 2004 shows that three countries, namely Italy, Germany, and France, account for more than $70 \%$ of the total outstanding amount of government bonds in the euro area. The same report shows that Luxembourg has no debt outstanding, while the sovereign of Ireland was very small. Those two countries are thus not part of our analysis.

${ }^{26}$ According to the study by ECB (2004), fixed-rate coupon bonds remain the most popular instrument capturing a $65 \%$ share of the total outstanding amount.

${ }^{27}$ See the European Securities Markets Expert Group (ESME) report published in 2006 for further details.

${ }^{28}$ An investor looking to buy or sell a bond can, again with a few exceptions, come to a bank and obtain a price at which the dealer is willing to sell or buy that bond.
} 
about trade size.

Like for many other securities, European Treasury markets have experienced a growing migration to electronic trading. A report by Greenwich Associates based on interviews with investment grade institutional investors, indicates that 39\% (resp. 47\%) of European government bonds are traded electronically in 2008 (resp. 2012). ${ }^{29}$ Besides, intermediation in the secondary Treasury market is still almost exclusively provided by traditional bank dealers, with little involvement of non-bank market-makers. ${ }^{30}$

The bond market data used in this study is from MTS Data, a product of MTS that is the most important electronic platform for euro-denominated government bonds. It consists of local MTS and a centralized EuroMTS. Persaud (2006) reports that the MTS platforms, around the sample period used in the empirical investigation, jointly cover just over $70 \%$ of the overall electronic trading of European government bonds (see also, Gyntelberg et al., 2013 and the references therein). Anecdotal evidence suggests that most of the trading in the electronic secondary market takes place in the local MTS while the amount of trading occurring on the centralized European MTS does not exceed $5 \%$ of the total trading. ${ }^{31}$ The MTS Data database has been extensively analyzed in previous studies (See Beber, Brandt and Kavajecz, 2009; Dufour and Nguyen, 2012; Pelizzon et al., 2016 and the references therein). Given the low ex post transparency on the European bond markets, it is however not possible to precisely quantify the market share of MTS relative to other OTC trading.

MTS is an inter-dealer, fully-electronic and quote-driven market characterized by a high degree of transparency. ${ }^{32}$ There are two types of market participants on the MTS platform:

\footnotetext{
${ }^{29}$ Source: https://www.greenwich.com/blog/electronic-trading-bonds-growing-\%E2\%80\%93-sort-of\%E2\%80\%A6.

${ }^{30}$ This contrasts with the situation in the U.S. where inter-dealer platforms have granted more lenient access to non-bank players, including PTFs (Principal Trading Firms), according to a report from the BIS (2016).

${ }^{31}$ A report on price discovery published in August 2010 by the Association for Financial Markets in Europe (AFME) indicates an average daily turnover on MTS of 85 billion euros (single counted and including repo).

${ }^{32}$ All platforms publish post-trade prices for trades conducted on their platforms on a realtime basis. In the case of inter-dealer platforms, these prices can only be viewed by platform participants. Exception is inter-dealer platform MTS, which makes post trade prices available to third parties through data vendors.
} 
"market makers" and "market takers." The liquidity is provided by dealers with specific market-making obligations. Market makers have to post firm two-sided quotes for a minimum size, a maximum spread and a minimum number of hours during the trading day. Once a quote is submitted to the network, it is ranked in the limit order book according to price-time priority rules and MTS publishes the best five quotes on either side of the book. Although MTS is considered as an "inter-dealer" platform, some participants (e.g. hedge funds) do not meet the requirements to be "market makers" and hence can only be eligible for a market taking status. MTS requires market takers to have net assets of at least 10 million euros. These participants can only use market orders to hit the best outstanding quotes. The minimum quantity for quotes and trades on MTS is one million euros. Executed trades are immediately and automatically reported.

\subsection{Data and summary statistics}

We focus on bonds that are traded at least 15 days in each of the three volatility regimes defined in the previous section. Our sample period spans from October 1st, 2004 to February 28th, 2011. ${ }^{33}$ We first collect the daily trading summaries of all European Treasury bonds that are traded in the platform EuroMTS provided by MTS Data. It involves the closing bond prices, yield, year-to-maturity, bond duration, the total trading volume as well as the number of market makers during the day. We then focus on bonds that are traded in the platform EuroMTS at least fifteen days in each of the three volatility regimes.

Table 1 reports the descriptive statistics of the government bonds. Panel (a) describes the statistics by country. We first collect some of the characteristics of each bond as it first appears in the sample, namely its yield, time to maturity, duration, coupon's rate and number of registered market makers. Statistics on the number of trades and trade size are computed over the whole sample period. Overall, we have 149 unique securities across the ten countries.

\footnotetext{
${ }^{33}$ Note that our sample period includes the recent 2008-2009 financial crisis but not the downgrade of Spain and Italy that took place on October 7, 2011.
} 
Bonds of most countries have an average duration between five and seven years. German bonds exhibit the lowest yields while those from Greece record the highest. Italian Treasury bonds have the highest trading volume. This may not be surprising since Mercato dei Titoli di Stato (MTS), the first venue for electronic trading of Treasury bonds, was indeed initially launched in 1988 by the Italian Treasury and the Bank of Italy, before EuroMST began its expansion across Europe in 1997. Bonds from Belgium, Finland, France, Germany, Greece and Italy exhibit a higher activity than bonds from other countries, measured in number of trades as well as in the number of participants. With the exception of Finland, this is in line with the fact that the amounts of debt outstanding of those countries are larger than those of the other countries. ${ }^{34}$

Panel (b) provides statistics on the cross-section of the 149 individual bonds (averaging measures per bond first). Bonds in our sample are characterized by a large heterogeneity, with a time to maturity spanning from 2.87 to 28.41 years, or a number of trades per week spanning from almost 7 to 620 . To further investigate the sources of heterogeneity, we report additional descriptive statistics on the bonds' characteristics. Haircuts required when the bond is used as a collateral are available for February 2011; our measure Haircut is computed as the average haircut per bond across time during this month. ${ }^{35}$ Haircuts are usually set as a function of the time to maturity, the coupon's structure and the credit quality of the issuer. It captures the cost of using the asset as collateral. The Credit Default Swap captures the Credit quality of the issuer. ${ }^{36}$ Finally, we introduce a proxy for the capacity of the sovereign bond to be used as a safe asset in a Flight to Quality episode. To this end, we first run individual bond regressions of the bond's weekly yield change on first difference of the

\footnotetext{
${ }^{34} \mathrm{ECB}$ (2007) mentions the following statistics on the outstanding nominal amounts of euro denominated public debt securities as of 2004, in billion euros: Austria 114.4, Belgium 254.2, Finland 54.8, France 891.9, Germany 1,006.6, Greece 158.8, Ireland 31.3, Italy 1,144.2, Netherlands 215.4, Spain 330.9, Portugal 72.9.

${ }^{35}$ Since April 2010, the list of eligible assets and associated haircuts can be obtained from the European Central Bank website https://www.ecb.europa.eu/paym/coll/assets/html/index.en.html.

${ }^{36} \mathrm{CDS}$ data is obtained for each country from Bloomberg covering the period from Oct 1, 2004 to Feb $28,2011$.
} 
average spread across the 5-year CDS contracts of all European countries (using data from Bloomberg). Our variable Flight To Quality is defined as the coefficient of the regression. A positive coefficient is usually expected: when the average credit quality decreases (i.e., when the CDS spreads increase), the bond's price decreases (i.e., its yield increases). A negative coefficient thus reveals that the bond is seen by investors as a safe-haven investment when there is a Flight-to-Quality episode. Accordingly, the dummy $D_{F t o Q}$ that takes value one if Flight to Quality is negative, and zero otherwise.

We find evidence of heterogeneity in haircuts (with an average haircut of $3.44 \%$ ), number of market makers (with an average number of 27 market makers per bond, that is, approximately half of the participants), and credit quality (with an average CDS od 27.65). Interestingly, we find that the average coefficient of the Flight-to-Quality regressions in our sample of bonds is negative and equal to -0.06 , which confirms that sovereign bonds are traditionally viewed as safe-haven investments. This heterogeneity across individual bonds in terms of activity and credit risk is one of the key advantages of our dataset on Treasury markets. We will exploit all aspects of this heterogeneity more in detail in the subsequent Section 4.5.

In our empirical investigation, our main measure of market illiquidity, the effective bidask spread, as well as two alternative proxies, namely the bid-ask spread and the price impact measures, are computed based on intraday data. In fact, the MTS Data database contains details of quotes and trades electronically recorded with time stamps accurate to the millisecond. The trades dataset records the execution price, quantity and the buy or sell direction for each transaction. The quotes dataset includes the proposed price and quantity up to the best three levels. In this study, we only consider quotes and trades during the trading hours (8:15 am - 5:30pm Central European Time). Overall, the dataset provides us with more than 500 million quote and trade observations (intraday) and 75,810 bond-weeks. From these intraday data, we construct the weekly time series for each bond in the sample. 
Our last proxy, Amihud's ILLIQ measure, is constructed on a weekly basis from daily data.

Table 2 reports summary statistics of the market illiquidity measures discussed in Section 3. In Panel (a), we report the mean and standard deviation (in parenthesis) across bonds by country. Both spread measures seem to be in line, but they do not rank countries in terms of market illiquidity similarly as Amihud's and the price impact measures. This suggests that various measures may capture different aspects of market liquidity. Quite intuitively, the effective spread seems to be higher in countries that are characterized by a higher average yield, a longer average time-to-maturity, or a lower number of trades per week. Interestingly, more participants do not seem to be linked to higher market liquidity.

Panel (b) reports the statistics of the distribution of the cross-section of bonds. In line with arguments suggesting strategic order submission from market participants, effective spread are on average lower than quoted spreads. Note that spreads are measured in basis points: an average effective spread of $3.74 \mathrm{bp}$ on an average transaction size of 7.11 million euros corresponds to a transaction cost of 2,659 euros. The large heterogeneity across bonds' liquidity measures in our sample echoes the heterogeneity on their characteristics documented in Table 1.

Panel (c) reports correlations between the various illiquidity measures. In line with existing studies, all measures are found to be highly correlated. Amihud's illiquidity measure is less correlated with the other measures than any other pair, with correlation coefficients with the three other measures ranging from 0.64 to 0.66 . Nonetheless, the correlations reported are large and economically significant. This suggests that our results should be robust to the choice of the market illiquidity measure.

We compute our main measure of funding illiquidity as well as two alternative proxies using data on OIS, Euribor and Repo rates from Thomson Reuters' Datastream. We use our dataset containing all bonds traded in EuroMTS to compute the Noise measure. Funding illiquidity measures are reported in Table 3, panel (a) but only the first two measures can 
be directly compared. The Euribor-Repo spread is on average higher than the Euribor-OIS spread, which reflects that the former measure may reflect changes in funding conditions that may not be only related to the counterparty risk of the institution but to changes in market conditions. All measures exhibit large standard deviations denoting some potential misspecification due to the estimation process and the variability of market interest rates.

Panel (b) of Table 3 reports the correlation among all funding illiquidity measures. All variables are significantly correlated at $1 \%$ level. The correlation between the noise measure and the Euribor-OIS spread is small, but it is highly correlated with the MRO, i.e., the central bank rate spread. ${ }^{37}$

\subsection{Systematic components of market and funding illiquidity}

In this section we discuss the construction of the systematic components FLIQ and $M L I Q$ as the first principal component of the relative menu of empirical proxies from both panels of funding and market illiquidity measures defined in section 3. The results reported in Table 4, panel (a) suggests that the first principal component of both panel of measures is sufficient to capture 81 and 57 percent of the cross-sectional variability of the market and funding illiquidity measures, respectively. This result echoes and corroborates the one reported in Korajczyk and Sadka (2008) where a single factor can explain between 4 and 26 percent of the variability of the cross-section of market liquidity proxies computed for individual equities. This result also suggests that there are significant commonalities driving the time-series variation of funding and market illiquidity in the European Treasury bond markets.

In panel (b), we notice that the factor loadings of all individual measures on their first principal component are positive and in the interval $[0.40,0.59]$. The second component of funding liquidity seems to be linked to the MRO and Noise measures, while the second com-

\footnotetext{
${ }^{37}$ The time series of all funding illiquidity proxies, not reported to save space, show that all measures increase at the end of 2009. This is in line with the timing of European sovereign bond crisis. See the next Section 4.3 for a discussion of the time-series dynamics of the systematic component of funding illiquidity.
} 
ponent of market liquidity is correlated with Amihud's ILLIQ measure. All other individual measures loads negatively to the second principal component. This suggests that the first principal component captures most of the relevant information.

Besides, correlations with the standard liquidity measures reported in Panel (c) all stand within an interval $[0.60,0.96]$. The Repo measure seems to be the most correlated with the systematic funding liquidity measure (i.e., with correlation coefficient of 0.88 ), while the effective spread seems to be the most correlated with the systematic market liquidity measure (i.e., with a correlation coefficient of 0.96).

\subsection{Empirical Results}

Figure 1 plots the time series of the market illiquidity measure in panel (a), and of the funding illiquidity measure in panel (b). It is worth noting that the estimated proxies for the two dimensions of liquidity are significantly correlated over time. In fact, the contemporaneous correlation between the systematic component of market and funding liquidity is equal to 0.71 and is statistically significant at 1 percent level. ${ }^{38}$ However, as highlighted in the previous sections, the intrinsic endogeneity between two variables may lead to spurious conclusions. We address and discuss this important issue in the next section.

Prior to estimating the reduced-form model, we first formally test that the time-series of the variables of interest exhibit heteroskedasticity. To this aim we use two tests that are routinely used to assess the null hypothesis of homoskedasticity: the White (1980) test and the Breusch-Pagan (1979) test. ${ }^{39}$ The results of the test are reported in Table 5, panel (a) and there is a unambiguous evidence that the liquidity proxies exhibit heteroskedasticity

\footnotetext{
${ }^{38}$ Similar calculations for the measures BAS, EBAS, IMP and ILLIQ against FLIQ record correlations equal to $0.71,0.70,0.63$, and 0.64 , respectively. Conversely, correlation coefficient computed for the EuriborOIS spread, the Euribor-Repo spread, the MRO-OIS spread, and the noise measure against MLIQ are equal to $0.40,0.47,0.78$, and 0.72 respectively.

${ }^{39}$ Note that the empirical tests adopted in this study are only two of the potential options available in the existing literature. However, we rely on those two approaches as they are routinely used in empirical works and, most importantly, because the goal of our study is not to find and empirically characterize any heteroskedasticity in the time-series of the illiquidity variables but exploit the existing heteroskedasticity to tackle the problem of endogeneity.
} 
over the sample period, whatever the measure of liquidity considered. This evidence allows us to confidently use the procedure discussed in Section 3.3.

Table 5, panel (b) reports the variances and covariances of the market and funding liquidity measures in the three regimes. The "low vStoxx" regime (12.31\% of our observations) is characterized by a low volatility of both market and funding liquidity measures. The "high vStoxx" regime (10.77\% of our observations) is characterized by a high volatility of both market and funding liquidity measures. The intermediate regime is characterized by a high volatility of funding liquidity (namely 0.38 , relative to 0.03 in the low vStoxx regime) but a relatively low volatility of market liquidity (namely 0.26 relative to 0.09 in the low vStoxx regime). The variances of the innovations when market and funding illiquidity are proxied by the effective spread and the Euribor-OIS spread respectively, reported in the three rows below, are qualitatively similar. The three regimes exhibit sufficient variation in volatilities that is required to identify our parameters of interest. Figure 1 plots the time series of funding and market liquidity measures and their residuals in the three different regimes. While the "high vStoxx" regime mainly corresponds to the peak of the financial crisis, observations in the two other regime do not correspond to a specific time period.

We finally estimate the reduced-form model discussed in Section 3.3 which now includes exogenous variables. ${ }^{40}$ In the empirical investigation we include as exogenous variables the mutual fund flows from Treasury bond portfolios, the variations in M2 money supply in the Euro area and the changes in the implied volatility obtained from stock market option prices in the euro-area, i.e the vStoxx index and the stock returns from financial companies. These variables aim at accounting for factors known to impact liquidity. The first two variables (i.e., mutual funds' flows and M2 money supply) aim at capturing variations in the borrowing capacities of financial institutions/arbitrageurs, either due to the size of the assets under management or to monetary policy. We proxy mutual funds' flow by inflows/outflows

\footnotetext{
${ }^{40}$ See Appendix 1 for full details.
} 
in billion USD in government bonds with intermediate and long maturities for the European countries, from EFPR reports. ${ }^{41}$ As the time series is reported at the monthly frequency, we use a linear interpolation to convert the variables to the weekly frequency. The data on variations in money supply M2 come from ECB's monetary statistics. We control for volatility since many market microstructure models suggest that volatility negatively impacts market liquidity (e.g., either due to inventory management or to adverse selection costs). Brunnermeier and Pedersen (2009) also predict that volatility is a state variable affecting market liquidity. Finally, we also include an end-of-the-month dummy to control for the discrete variation of European repo rates during the last trading day of each month. This choice is due to the empirical observation of European banks that are required to report their positions to the European Central Bank on the last trading day of each month. To complete the set of exogenous variables we also include the lagged values of the systematic funding and market illiquidity variables.

The results are reported in Table 6. The first two columns report the results of the estimation using MLIQ and FLIQ as principal components, and the last two columns report those using EBAS and Euribor-OIS as measures of market and funding illiquidity. Contemporaneous shocks to funding illiquidity are found to significantly affect the average market illiquidity across all local European Treasury bond markets. The reverse causality link also applies as contemporaneous shocks to our proxy of market illiquidity significantly affects funding illiquidity in the European Treasury markets. Both effects are sizable and economically significant whether one considers the principal components or the direct proxies of liquidity. When one considers the systematic measures, one standard deviation shock to funding liquidity (i.e. relaxation of funding constraints) generates a contemporaneous improvement of market liquidity of 0.151 standard deviation across Treasury bond markets in Europe, while one standard deviation shock to systematic market illiquidity generates a

\footnotetext{
${ }^{41}$ For further details on EPFR reports see also Jotikasthira et al. (2012) and the references therein
} 
contemporaneous change of 0.080 standard deviation in funding illiquidity. Using the direct proxies, one standard deviation decrease of the Euribor-OIS spread (that is, a decrease by 9.92 basis points) generates a contemporaneous decrease 0.35 bps of the effective bid-ask spreads across Treasury bond markets in Europe (that is, 0.120 times $2.92 \mathrm{bp}$ ), which correspond to an improvement of $9 \%$ relative to the average effective spread. A one standard deviation decrease in effective bid-ask spreads (that is, $2.92 \mathrm{bp}$ ) generates a contemporaneous decrease of the Euribor-OIS spread of $0.32 \mathrm{bps}$ (that is, 0.033 times $9.92 \mathrm{bp}$ ), which corresponds to an improvement of $5.2 \%$ relative to the average Euribor-OIS spread. This result documents that there indeed a feedback effect from market to funding liquidity. Brunnermeier and Pedersen (2009)'s model is however characterized by multiple equilibria, one of which is characterized by the reinforcement of market and funding liquidity. We find that both $\beta$ and $\alpha$ are positive, which is consistent which such an equilibrium. This is important because this equilibrium may yield liquidity spirals.

Mutual funds' net inflows and an increase in M2 money supply significantly reduce market illiquidity. Both signs are consistent with the prediction that higher "macroeconomic" liquidity increases market liquidity. Their impact on funding illiquidity is however not significant. This finding may seem counter-intuitive; it is however in line with Chordia et al. 2005, who show that those variables are responsible for the commonalities in market liquidity measures. Stock market volatility (vStoxx) is positively and significantly related to bond market illiquidity but not to funding illiquidity. Consistent with much anecdotal evidence, we find that funding illiquidity significantly increases at the end of the month. This supports the argument that European banks are reluctant to lend to each other at the end of the month for reporting reasons, therefore, funding liquidity is reduced. 


\subsection{Bond characteristics and liquidity elasticities: a cross-sectional analysis}

The results reported in Table 6 provide evidence that, after controlling for endogeneity, funding illiquidity positively impacts market illiquidity, and vice-versa. Two mechanisms could be at play to explain this finding. First, constraints on access to capital of market makers would impact the risk premium required to hold an inventory position. Second, constraints on access to capital of hedge funds or arbitrageurs may decrease market liquidity because they use to absorb the investors' demand. In particular, Garleanu and Pedersen (2011) show that market liquidity may depend on margin requirements. In this section, we take advantage of the existence of different margin requirements across maturities or across countries to test the link between margin conditions and the strength of the relationship between funding and market liquidity.

To this end, we define two measures of bond market illiquidity per bond, one that is based on the direct market liquidity proxy that will be used with the funding liquidity measure defined as a direct component, and the other that builds on the market liquidity measure $M L I Q$ that will be used with the funding liquidity measure defined as first principal component. We first consider the direct measure of market liquidity, the effective bid-ask spread $E B A S_{j, t}$ that we have computed for each individual bond $j$, and its mean $E B A S_{j}$. The market illiquidity of bond $j, S E B A S_{j, t}$ is then defined as follows:

$$
S E B A S_{j, t}=E B A S_{j, t}-E B A S_{j}
$$

The $S E B A S_{j}$ proxy is demeaned which enables a better comparison of the estimates. Notice however that is does not distinguish between the systematic and the idiosyncratic components of market liquidity. Next, we consider the $M L I Q_{t}$ variable defined in section 3.1 as the first principal component of the cross-sectional averages of our four proxies for market liquidity, as the systematic component of each bond's market liquidity. For each individ- 
ual bond $j$, we compute the total market illiquidity measure $M L I Q_{j, t}$ as the first principal component of the four proxies of market liquidity, namely the bid-ask spread, the effective spread, Amihud's illiquidity and the price impact, measured at the individual bond level. The idiosyncratic market illiquidity of bond $j, \operatorname{Idio} M L I Q_{j, t}$ is then defined as follows:

$$
I \operatorname{dioMLIQ} Q_{j, t}=M L I Q_{j, t}-M L I Q_{t}
$$

We use the individual variables to carry out the estimations in the reduced form model used in Section 3.3. We estimate the same specification that includes lags of illiquidity variables and the set of control variables. This exercise provides us with a cross-sectional panel of contemporaneous coefficients $\left(\alpha_{j}, \beta_{j}\right)$. Table 7 , panel (a) reports statistics on the distribution of these coefficients. Using the $I$ dioMLIQ $Q_{j}$ idiosyncratic measure, the average of individual $\beta_{j}$ 's is much smaller than the estimate of $\beta$ in the global estimation. It thus seems that funding illiquidity mainly impacts the systematic component of market illiquidity, $M L I Q$, rather than the idiosyncratic illiquidity of each bond. Note also that we do not necessarily expect a significantly positive $\alpha$ when considering the idiosyncratic component of market liquidity only; we are mainly interested in the factors explaining its cross-sectional variations.

We then use the estimates of $\left(\alpha_{j}, \beta_{j}\right)$ to analyze what variables impact the two elasticities in the cross section of bonds. To this end, we run the following regression on the bond panel using $Y_{j}=\left(\alpha_{j}, \beta_{j}\right)$ :

$$
Y_{j}=a_{0}^{Y}+a_{1}^{Y} \times \text { Duration }+a_{2}^{Y} \times C D S+\varepsilon_{j}^{Y}
$$

All measures are defined in Section 4.2. Our pool of explanatory variables for the coefficient $\beta$ of the impact of funding on market illiquidity comes from the theoretical literature. According to Brunnermeier and Pedersen (2009), when funding illiquidity increases, traders become reluctant to take on positions, especially capital intensive positions in high-margin 
securities. We therefore include the Duration and the credit risk of the issuer $C D S$ as explanatory variables (first individually then together), and we expect both of them to positively impact the betas, that is, $a_{1}^{\beta}>0$ and $a_{2}^{\beta}>0$. Both variables influence the haircuts on the bond. As described in Section 4.2, we however only have data on haircuts on February 2011 for the bonds that did not mature at that date. ${ }^{42}$ In a second specification, we therefore replace Duration and $C D S$ by Haircut.

$$
Y_{j}=b_{0}^{Y}+b_{1}^{Y} \times \text { Haircut }+\varepsilon_{j}^{Y} .
$$

We expect the coefficient $b_{1}^{\beta}$ to be positive. Finally, Brunnermeier and Pedersen (2009) suggest that if investors anticipate that some risky high-margin securities would have more liquidity risk, the liquidity differential between high-volatility and low-volatility securities may increase in bad times. We thus add as explanatory variable the exposure of securities to Flight to Quality, and we expect our dummy $D_{F t o Q}$ to have an impact on the magnitude of the effect of funding to market liquidity.

$$
Y_{j}=c_{0}^{Y}+c_{1}^{Y} \times D_{F t o Q}+\varepsilon_{j}^{Y}
$$

The dummy takes value one when the security is perceived as safer by the investors. For this reason, we expect $c_{1}^{\beta}<0$.

The theoretical literature is more silent on the drivers of $\alpha$ which captures the impact of market on funding illiquidity. We thus use the same explanatory variables as in the regressions of $\beta$. The main prediction comes from the model of Brunnermeier and Pedersen (2009): if the feedback effect from market to funding illiquidity is due to the use of securities as collaterals, it should be more severe for securities that do not use much capital, i.e., that have a low haircut, a high duration, or a high CDS. We thus expect $a_{1}^{\alpha}<0, a_{2}^{\alpha}<0$, and $b_{1}^{\alpha}<0$.

\footnotetext{
${ }^{42}$ Haircuts are highly and significantly correlated with bond duration and CDS (with a correlation coefficient of 0.6 for both).
} 
The results of the two cross-sectional regressions for both $\alpha$ and $\beta$ are reported in Table 7, panels (b) and (c). As expected, the impact of funding liquidity on market liquidity $(\beta)$ significantly increases with duration, with credit risk, with the bond's haircut, and decreases

significantly when bonds are perceived as safer assets. Overall, the market liquidity of the bonds that are less liquid or perceived as such is more affected by variations in funding liquidity, in line with theory.

By contrast, duration, credit risk, and haircuts have an opposite effect on the $(\alpha s)$ coefficients. In particular, we find that $\alpha$ 's significantly decrease with haircut. This is consistent with the fact that bonds that have a higher haircut are probably used less frequently as collateral, so that variations in market liquidity for the latter impact less funding liquidity. Interestingly, bonds that are viewed as safe in Flight To Quality episodes soften the magnitude of the effect of market liquidity on funding liquidity.

\section{Robustness checks}

We perform a number of additional tests to assess the robustness of our baseline results. More specifically, we investigate the role played by the sample of bonds used in the empirical exercise, we use a different volatility-regime classification, we estimate the model by splitting our sample into two subsamples (one before and one during the financial crisi), and we estimate an alternative parametrization of the reduced-form model. In all cases, we document that the baseline results reported in the previous section are robust to alternative choices.

\subsection{Sample of bonds}

As described in section 4.2, our analysis focuses on a subsample of 149 bonds that are traded in the platform EuroMTS at least fifteen days in each of the three volatility regimes, defined exogenously based on variation in the vStoxx index. This restriction enables us to compare estimates of $\alpha_{j}$ and $\beta_{j}$ in the cross-section of bonds since all the estimations are based on 
the same volatility regimes. However, it induces us to restrict our attention to a subsample of bonds. In this section, we check the robustness of our results to the sample of bonds, by estimating the reduced-form model using an extended sample of 452 bonds traded in EuroMTS over the sample period.

Table 8, Panel (a) reports some descriptive statistics on the full sample, by country. The comparison with Table 1, Panel A shows that the characteristics of the bonds by country in the subsample are similar to those in the full sample, except for the fact that they have on average shorter years-to-maturity and duration. Given that the subsample requires trades in each volatility regime, it may not be surprising to observe that the condition mainly excludes bonds with shorter maturities. Including more bonds with shorter maturities increases the trading volume of all but Finish bonds.

We estimate the model for the direct proxies of market and funding liquidity, and for the measures defined as the first principal components. We construct systematic components $F L I Q$ and $M L I Q$ from both panels of funding and market illiquidity measures across proxy measures and Treasury bond markets by a adopting principal components approach. The results (omitted for brevity) suggest that the first principal component of both panels captures 57 and 75 percent of the cross-sectional variability of the funding and market illiquidity measures, respectively. Besides, the heteroskedasticity tests also reject the null for both FLIQ and MLIQ at the $1 \%$ level.

Table 8, Panel (b) reports the estimates of the reduced-form model similar to the one discussed in Section 4.4. The results are perfectly in line with those reported in Table 6, although slightly less economically significant. In particular, both effects of funding to market illiquidity and vice-versa are positive and significant, with coefficients of $0.06-0.07$ (depending on the liquidity measures) for $\beta$ and 0.05 for $\alpha$ respectively. 


\subsection{Different Volatility-regime Classification}

As an additional robustness check we identify the volatility regimes directly from the timeseries data. More specifically, we define the various regimes from the reduced-form residuals by computing rolling-window variances of $\mathrm{N}$-week worth of observations for each variable. As in Rigobon and Sack (2003), a high (low) volatility regime is assigned if the volatility of that variable is larger (smaller) than its average value plus the value of the average volatility times a coefficient $c$.

We report the results of the estimation using a moving-average estimate of volatility for the various time series of $N=20$ weeks with a threshold parameter $c=0.5 .{ }^{43}$

Table 11 A reports the results of the estimation of the reduced-form model defined in (3) on the sample of 149 bonds and on the full sample, for the direct measures of illiquidity and the first principal components. Again, both effects of funding to market illiquidity and vice-versa are positive and significant. The coefficients of 0.150 for $\beta$ and 0.067 for $\alpha$ for the subsample that we obtain when using principal component measures, and of 0.132 for $\beta$ and 0.04 for $\alpha$ for the full sample, are very close from the values obtained with the alternative definition of volatility regimes.

\subsection{Stability of the estimates}

The Identification by Heteroskedasticity is based on the assumption that parameters $\alpha$ and $\beta$ are constant over time, which may be violated. In particular, the impact of funding on market liquidity or its feedback effect may be different in abnormal times. To investigate this point, we split our sample into two subsamples around Lehman Brother's bankrupcty in the fall of 2008, and we re-estimate the model on each of these subsamples. ${ }^{44}$ Table 9

\footnotetext{
${ }^{43}$ We have used additional rolling windows of 10,30 and 40 weeks to estimate the volatility of the various time series and additional thresholds of $c=0.25,0.75,1.0$ to classify high-volatility regimes. The results of this robustness check are available upon request. In all cases, the results of our baseline estimations are confirmed.

${ }^{44}$ For brevity we do not report the details of the characteristics of these two subsamples, nor descrptive statistics on the liquidity measures or on volatility regimes by period. These statistics are available upon
} 
reports the results. We observe that the estimates of both parameters of interest $(\alpha$ and $\beta)$ are quite similar both economically and statistically before and during the financial crisis, except for the market to funding coefficient $(\alpha)$ computed usinf the individual measures of market and funding liquidity (namely the effective spread and the Euribor-OIS spread), that is not significant at the $10 \%$ level during the crisis.

To further investigate the stability of the estimates, we follow Rigobon (2016) and use a test based on quintile regressions. The test is based on the idea that the instability of the parameters would create a non-linearity in the estimates. In that case, estimates should shift across the quintiles. Table 10 presents the test for stability across quintile in the relation between the market liquidity of bond $j$ and the funding liquidity. p-values indicate that we cannot reject the equality of the median and respectively the $70 \%, 80 \%$ and $95 \%$ quintiles at the $10 \%$ level. Overall, Table 9 and Table 10 suggest that the assumption on the parameters' stability would not be a concern.

\subsection{Alternative models}

As an additional robustness check we estimate an alternative model, based on Rigobon and Sack (2003). The model includes an unobservable common shock, which accounts for potential omitted control variables, but prevents from estimating the parameter $\alpha$, measuring the impact of market liquidity on funding liquidity. Instead, the model provides an estimate of a parameter $\theta$, which is defined as

$$
\theta=\frac{(1+\alpha \times \gamma)}{\beta+\gamma}
$$

where $\gamma$ is the coefficient of the unobserved variable. Table 12 reports the estimates of this model, for both the subsample of 149 bonds and the full sample, for both approaches to measuring market and funding illiquidity. In both cases, the effects of funding to market illiquidity and vice-versa are positive, significant, and relatively close to that obtained in our request. 
model based on Rigobon (2003).

\section{Conclusions}

This paper adopts an identification technique based on the heteroskedasticity of illiquidity measures to infer the magnitude of the impact of market illiquidity to and from funding illiquidity by taking the endogeneity of the illiquidity measures explicitly into account. Using data for the European Treasury bond market, we find evidence, consistent with the extant literature, that funding illiquidity shocks affect bond market illiquidity. However, we document the existence of a positive and significant feedback between market and funding illiquidity: put differently, market illiquidity shocks tighten funding constraints. We exploit the heterogeneity of our sample of bonds, characterized by different durations and default risk, to investigate the determinants of the magnitude of these effects. We find that the market-to-funding illiquidity effect is stronger for short-term bonds and for bonds used as collaterals in repo transactions. Our results are robust to alternative definitions of the volatility regimes, alternative samples of bonds, and alternative model specifications. Our findings suggests the presence of destabilizing liquidity spirals. As shown by Brunnermeier and Pedersen (2009), central banks can help mitigate market liquidity problems in such equilibria by boosting speculators' funding conditions during a liquidity crisis. 


\section{Appendix 1}

The appendix follows the identification strategy in the Section 3.3. The covariance matrix of the reduced-form residuals in (1) model in each regime $i(i=1, \ldots, I$ volatility regimes) can be given as:

$$
\begin{aligned}
\Omega_{i} & \equiv\left[\begin{array}{cc}
\varpi_{11, i} & \varpi_{12, i} \\
\cdot & \varpi_{22, i}
\end{array}\right] \\
& =\frac{1}{(1-\alpha \beta)^{2}}\left[\begin{array}{cc}
\beta^{2} \sigma_{\eta, i}^{2}+\sigma_{\epsilon, i}^{2} & \beta^{2} \sigma_{\eta, i}^{2}+\alpha \sigma_{\epsilon, i}^{2} \\
\cdot & \sigma_{\eta, i}^{2}+\alpha^{2} \sigma_{\epsilon, i}^{2}
\end{array}\right],
\end{aligned}
$$

where $\alpha \beta \neq 1$. In each regime, the covariance matrix provides three equations to solve the unknown variables. The three equations can be written as follows:

$$
\begin{aligned}
\beta^{2} \sigma_{\eta, i}^{2}+\sigma_{\epsilon, i}^{2} & =(1-\alpha \beta)^{2} \varpi_{11, i} \\
\beta^{2} \sigma_{\eta, i}^{2}+\alpha \sigma_{\epsilon, i}^{2} & =(1-\alpha \beta)^{2} \varpi_{12, i} \\
\sigma_{\eta, i}^{2}+\alpha^{2} \sigma_{\epsilon, i}^{2} & =(1-\alpha \beta)^{2} \varpi_{22, i}
\end{aligned}
$$

Solving these equations leads to the following moment condition:

$$
\frac{\varpi_{12, i}-\beta \varpi_{22, i}}{\varpi_{11, i}-\beta \varpi_{12, i}}-\alpha=0
$$

When the number of volatility regimes $I$ is exactly the same as the number of endogenous variables, i.e. two in our case, $\beta$ needs to statistfy the following condition:

$$
\frac{\varpi_{12,1}-\beta \varpi_{22,1}}{\varpi_{11,1}-\beta \varpi_{12,1}}=\frac{\varpi_{12,2}-\beta \varpi_{22,2}}{\varpi_{11,2}-\beta \varpi_{12,2}}
$$

After some algebra, $\beta$ solves the quadratic equation ${ }^{45}$ :

\footnotetext{
${ }^{45}$ The quadratic equation has two solutions. One is the values of $\alpha$ and $\beta$ in the system of equation. The other is given as the system in which the order of funding liquidity is first and then market liquidity. In that case, the solution gives the values $\alpha^{*}=1 / \beta$ and $\beta^{*}=1 / \alpha$.
} 


$$
a \beta^{2}-b \beta+c=0
$$

where

$$
\begin{aligned}
a & =\varpi_{22,1} \times \varpi_{12,2}-\varpi_{22,2} \times \varpi_{12,1} \\
b & =\varpi_{22,1} \times \varpi_{11,2}-\varpi_{22,2} \times \varpi_{11,1} \\
c & =\varpi_{12,1} \times \varpi_{11,2}-\varpi_{12,2} \times \varpi_{11,1}
\end{aligned}
$$

When the regimes of volatility $I$ is exactly greater than the number of endogenous variables, GMM estimation can be used with the moment condition specified as above. 


\section{Appendix 2}

This appendix discusses an extension of the reduced-form model presented in Section 3.3 of the main text by including exogenous variables. As Rigobon (2003) and Rigobon and Sack (2003) we start from the observation that market and funding liquidity are determined simultaneously and we model their time-series dynamics by using the following system:

$$
\begin{aligned}
m_{t} & =\beta f_{t}+\theta x_{t}+\gamma z_{t}+\epsilon_{t}, \\
f_{t} & =\alpha m_{t}+\phi x_{t}+z_{t}+\eta_{t},
\end{aligned}
$$

where $m_{t}$ is the systematic component of market illiquidity, $f_{t}$ is the systematic component of funding illiquidity, $x_{t}$ is a vector of exogenous variables, $z_{t}$ is a latent variable, $\epsilon_{t}$ and $\eta_{t}$ are shocks in each equation. The variable $z_{t}$ is included to capture the influence of other determinants of illiquidity that we do not observe, unlike $x_{t}$ that are instead observable. For identification purposes, as in Rigobon and Sack (2003, p. 643) the parameter of the common shock $z_{t}$ is normalized to one in the second equation while $\beta, \alpha, \theta, \phi$ are the free parameters of the model.

The equations can be written in a reduced-form model as follows:

$$
\left(\begin{array}{c}
m_{t} \\
f_{t}
\end{array}\right)=\Phi x_{t}+\left(\begin{array}{c}
\nu_{t}^{m} \\
\nu_{t}^{f}
\end{array}\right)
$$

where the reduced form residuals $\left(\nu_{t}^{m}\right.$ and $\left.\nu_{t}^{f}\right)$ are related to the structural shocks as follows:

$$
\begin{aligned}
\nu_{t}^{m} & =\frac{1}{1-\alpha \beta}\left[(\beta+\gamma) z_{t}+\beta \eta_{t}+\epsilon_{t}\right] \\
\nu_{t}^{f} & =\frac{1}{1-\alpha \beta}\left[(1+\alpha \gamma) z_{t}+\eta_{t}+\alpha \epsilon_{t}\right]
\end{aligned}
$$

The covariance matrix of the reduced-form residuals can be given as: 


$$
\Omega=\frac{1}{(1-\alpha \beta)^{2}}\left[\begin{array}{cc}
(\beta+\gamma)^{2} \sigma_{z}^{2}+\beta^{2} \sigma_{\eta}^{2}+\sigma_{\epsilon}^{2} & (1+\alpha \gamma)(\beta+\gamma) \sigma_{z}^{2}+\beta^{2} \sigma_{\eta}^{2}+\alpha \sigma_{\epsilon}^{2} \\
\cdot & (1+\alpha \gamma)^{2} \sigma_{z}^{2}+\sigma_{\eta}^{2}+\alpha^{2} \sigma_{\epsilon}^{2}
\end{array}\right]
$$

We assume that the data exhibits $i=1, \ldots, I$ volatility regimes, of which the covariance matrix of the reduced form residuals in regime $i$ can be written as $\Omega_{i}$. Let $\theta=$ $(1+\alpha \gamma) /(\beta+\gamma)$. and $\Delta \Omega_{i j, k m}$ denote element $(k, m)$ of the matrix $\Delta \Omega_{i j}$, which is the difference between the covariance matrix in regime $i$ and regime $j$. If $\theta \beta \neq 1$, which assures finite variance, Rigobon and Sack (2003) suggests the following moment conditions with regime $i(i \neq 1)$ :

$$
\frac{\Delta \Omega_{i 1,12}-\beta \Delta \Omega_{i 1,22}}{\Delta \Omega_{i 1,11}-\beta \Delta \Omega_{i 1,12}}-\theta=0
$$

When the number of volatility regime $I$ is exactly the same as the number of endogenious variables plus the number of common shock, Rigobon and Sack (2003) shows that the parameter $\beta$ can be obtained by solving the quadratic equation:

$$
a \beta^{2}-b \beta+c=0
$$

where

$$
\begin{aligned}
a & =\Delta \Omega_{31,22} \Delta \Omega_{21,12}-\Delta \Omega_{21,22} \Delta \Omega_{31,12} \\
b & =\Delta \Omega_{31,22} \Delta \Omega_{21,11}-\Delta \Omega_{21,22} \Delta \Omega_{31,11} \\
c & =\Delta \Omega_{31,12} \Delta \Omega_{21,11}-\Delta \Omega_{21,12} \Delta \Omega_{31,11}
\end{aligned}
$$

If the number of $I$ is greater than the number of endogenious variables plus the number of common shock, GMM estimation technique needs to be applied. Using the rolling-variance method, we specify $I=4$ volatility regimes, one where the two liquidity measures demonstrate high conditional volatility, two regimes where one variable remains in low volatility state, one regime where all variables stay in low volatility state. We obtain the parameters 
by using the (23) moment conditions in the GMM estimation. We establish the distributions of the estimated coefficients and perform significance tests in 1000 replications. 


\section{References}

Adrian, Tobias, Erkko Etula, and Tyler Muir, 2014, Financial intermediaries and the crosssection of asset returns, Journal of Finance 69, 2557-2596.

Admati, Anat R., and Paul Pfleiderer, 1988, A Theory of Intraday Patterns: Volume and Price Variability, The Review of Financial Studies, 1, 3-40.

Amihud, Yakov, and Haim Mendelson, 1986, Asset pricing and the bid-ask spread, Journal of Financial Economics 17, 223-249.

Aragon, George O., and Philip E. Strahan, 2012, Hedge funds as liquidity providers: Evidence from the Lehman bankruptcy, Journal of Financial Economics 103, 570-587.

Baba, Naohiko, and Frank Packer, 2009, From turmoil to crisis: dislocation in the FX swap market before and after the failure of Lehman Brothers, Journal of International Money and Finance 28, 1350-1374.

Beber, Alessandro, Michael W. Brandt, and Kenneth A. Kavajecz, 2009, Flight-to-Quality or Flight-to-Liquidity? Evidence from the Euro-Area Bond Market, The Review of Financial Studies 22, 925-957.

Bessembinder, Hendrik, Stacey Jacobsen, Willilam Maxwell, and Kumar Venkatamaran, 2016, Capital commitment and illiquidity in corporate bonds, Working paper, available at SSRN.

Boudt, Kris, Ellen C.S. Paulus, and Dale W.R. Rosenthal, 2013, Funding liquidity, market liquidity and TED spread: A two-regime model, NBB Working paper $n^{\circ} 244$.

Brennan, Michael J., and Avanidhar Subrahmanayam, 1996, Market microstructure and asset pricing: On the compensation for illiquidity in stock returns, Journal of Financial Economics 41, 441-464.

Breusch, T.S., and A.R. Pagan, 1979, A simple test for heterosckedasticity and random coefficient variation, Econometrica 47, 1287-1294.

Brogaard, Jonathan, Terrence Hendershott, and Ryan Riordan, 2014, High-Frequency Trad- 
ing and Price Discovery, The Review of Financial Studies 27, 2267-2306.

Brunnermeier, Markys K., and Lasse Heje Pedersen, 2009, Market Liquidity and Funding Liquidity, The Review of Financial Studies 22, 2201-2238.

Chordia, Tarun, Asani Sarkar, and Avanidhar Subrahmanyam, 2005, An Empirical Analysis of Stock and Bond Market Liquidity, Review of Financial Studies 18, 85-130.

Coffey, N., W. Hrung, and A. Sarkar, 2009, Capital Constraints, Counterparty Risk and Deviations from Covered Interest Rate Parity, Working Paper, The Federal Reserve Bank of New York.

Comerton-Forbe, Carole, Terrence Hendershott, Charles M. Jones, Pamela C. Moulton, and Mark S. Seaholes, Time variation in liquidity: the role of market-maker inventories and revenues, Journal of Finance 65, 295-332.

Coughenour, Jay F., and Mohsen M. Saad, 2004, Common market makers and commonality in liquidity, Journal of Financial Economics 73, 37-69.

Deuksar, Prachi, and Timothy C. Johnson, 2016, Central banks and dynamics of bond market liquidity, Working paper, availlable at SSRN.

Demsetz, Harold, 1968, The cost of transacting, Quarterly Journal of Economics 82, 33-53.

Dick-Nielsen, Jens, Jacob Gyntelberg, 2013, From Funding Liquidity to Market Liquidity: Evidence from Danish bond markets, presented at the Midwest Finance Association 2014 Annual Meeting.

Drehman, Mathias, and Kleopatra Nikolaou, 2013, Funding liquidity risk: definition and measurement, Journal of Banking and Finance 37, 2173-2182.

Dudley, William C., 2016, Market and Funding Liquidity: An Overview, Remarks at the Federal Reserve Bank of Atlanta 2016 Financial Market Conference.

Dufour, Alfonso, and Minh Nguyen, 2012, Permanent Trading Impacts and Bond Yields, Working Paper, University of Reading.

Dunne, Peter G., Michael J. Fleming, and Andrey Zholos, 2013, ECB Monetary Operations 
and the Interbank Repo Market, Federal Reserve Bank of New York Staff Reports 654.

D'Souza and Lai, 2006, The effects of bank consolidation on risk capital allocation and market liquidity The Journal of Financial Research 29, 271-291.

Fleming, Michael, 2003, Measuring Treasury Market Liquidity, Federal Reserve Bank of New York Economic Policy Review 9, 83-108.

Foucault, Thierry, Marco Pagano, and Ailsa Roell, 2013, Market Liquidity: Theory, Evidence, and Policy, Oxford University Press.

Fontaine, Jean-Sebastien, and Rene Garcia, 2012, Bond Liquidity Premia, The Review of Financial Studies 25, 1207-1254.

Fontaine, Jean-Sebastien, Rene Garcia, end Sermin Gunkor, 2016, Funding Liquidity, Market Liquidity and the Cross-Section of Stock Returns, Working paper, CIRANO scientific series.

Garleanu, Nicolae and Lasse H. Pedersen, 2011, Margin-based Asset Pricing and Deviations from the Law of One Price, The Review of Financial Studies 24, 1980-2022.

Geanakoplos, John, 2003, Liquidity, Default, and Crashes: Endogenous Contracts in General Equilibrium, in Advances in Economics and Econometrics: Theory and Applications II, Econometric Society Monographs: Eighth World Congress, ed. M. Dewatripont, L. P. Hansen, and S. J. Turnovsky. Cambridge, UK: Cambridge University Press, 170-205.

Goyenko, Ruslan Y., Craig W. Holden, and Charles A. Trzcinka, 2009, Do liquidity measures measure liquidity?, Journal of Financial Economics 92, 153-181.

Gromb, Denis, and Dimitri Vayanos, 2002, Equilibrium and welfare in markets with financially constrained arbitrageurs, Journal of Financial Economics 66, 361-407.

Gyntelberg, Jacob, Hordahl, Peter, Ters, Kristyna and Jorg Urban, 2013, Intraday Dynamics of Euro Area Sovereign CDS and Bonds, BIS Working Paper N. 423.

Hameed, Allaudeen, Wenjin Kang, and S. Viswanathan, STock market declines and liquidity, The Journal of Finance 65, 257-293. 
Hasbrouck, Joel, 1991, Measuring the Information Content of Stock Trades, The Journal of Finance 46, 179-207.

He, Zhiguo, and Arvind Krishnamurthy, 2012, A model of capital and crises, The Review of Economic Studies 79, 735-777.

He, Zhiguo, and Arvind Krishnamurthy, 2013, Intermediary asset pricing, American Economic Review 103, 732-770.

Hedegaard, Esben, 2014, Causes and consequences of margin levels in futures markets, $A Q R$ working paper.

Hu, Grace Xing, Jun Pan, and Jiang Wang, 2013, Noise as information for illiquidity, The Journal of Finance 68, 2341-2382.

Huh, Yesol, and Sebastian Infante, 2016, Bond Market Liquidity and the Role of Repo, Working paper, Federal Reserve Board.

Ho, Thomas, and Hans R. Stoll, 1981, Optimal dealer pricing under transactions and return uncertainty, Journal of Financial Economics 9, 47-73.

Hördahl, Peter, and Michael R. King, 2008, Developments in repo markets during the financial turmoil, BIS Quarterly Review, Bank for International Settlements.

Jensen, Gerald R., and Theodore Moorman, 2010, Inter-temporal variation in the illiquidity premium, Journal of Financial Economics 98, 338-358.

Jylh'a, Petri, 2015, Does Funding Liquidity Cause Market Liquidity? Evidence from a QuasiExperiment, Working Paper, Imperial College Business School.

Jotikasthira, C. Lundblad C., and Tarun Ramadorai, 2012, Asset Fire Sales and Purchases and the International Transmission of Funding Shocks, Journal of Finance 67, 2015-2050. Kahramand, Bige, and Heather E. Tookes, 2016, Trader leverage and liquidity, The Journal of Finance, forthcoming.

Kitsul, Yuriy, and Marcelo Ochoa, 2016, Funding Liquidity Risk and the Cross-section of MBS Returns, Working Paper, Federal Reserve Board. 
Korajczyk, Robert and Ronnie Sadka, 2008, Pricing the Commonality Across Alternative Measures of Liquidity, Journal of Financial Economics 87, 45-72.

Krishnamurthy, Arvind, Stefan Nagel, and Dmitry Orlov, 2014, Sizing Up Repo, The Journal of Finance 69, 2381-2417.

Kyle, Albert S., and Wei Xiong, 2001, Contagion as a wealth effect, The Journal of Finance 61, 1401-1440.

Lee, Charles, 1993, Market Integration and Price Execution for NYSE Listed Securities, The Journal of Finance 48, 1009-1038.

Lescourret, Laurence, and Christian Y. Robert, 2011, Transparency matters: price formation in presence of order preferencing, The Journal of Financial Markets 120, 113-125.

Malz, Allan, 2003, Liquidity risk: Current research and practice, RiskMetrics 4, 35-72.

Mancini Griffoli, Tommaso, and Angelo Ranaldo, 2010, Limits to arbitrage during the crisis: funding liquidity constraints and covered interest parity, Swiss National Bank Working Papers 2010-14.

Mancini, Loriano, Angelo Ranaldo, and Jan Wrampelmeyer, 2015, The Euro Interbank Repo Market, The Review of Financial Studies, forthcoming.

Miglietta, Arianna, Cristina Picillo, and Mario Pietrunti, 2015, The impact of CCPs' margin policies on repo markets, BIS Working Papers n 515 .

Musto, David, Greg Nini, and Krista Schwartz, 2015, Notes on Bonds: Liquidity at all Costs in the Great Recession, Working Paper, University of Pennsylvania.

Nagel, Stefan, 2012, Evaporating liquidity, The Review of Financial Studies 25, 2005-2039.

Pelizzon, Loriana, Marti G. Subrahmanyam, Davide Tomio, and Jun Uno, 2016, Sovereign Credit Risk, Liquidity, and ECB Intervention: Deus ex Machina?, Journal of Financial Economics forthcoming.

Persaud, A.D., 2006, Improving Efficiency in the European Government Bond Market, Discussion Paper ICAP plc. 
Rigobon, Roberto, 2003, Identification through Heteroskedasticity, The Review of Economics and Statistics 85, 777-792.

Rigobon, Roberto, 2016, Contagion, spillover and interdependence, Bank of England Staff Working Paper No. 60\%.

Rigobon, Roberto, and Brian Sack, 2003, Measuring the reaction of monetary policy to the stock market, The Quarterly Journal of Economics, 639-669.

Rigobon, Roberto, and Brian Sack, 2004, The Impact of Monetary Policy on Asset Prices, Journal of Monetary Economics 51, 1553-1575.

Shleifer, Andrei, and Robert W. Vishny, 1997, The Limits of Arbitrage, The Journal of Finance 52, 35-55.

Schwartz, Krista, 2016, Mind the Gap: Disentangling Credit and Liquidity in Risk Spreads, Working paper, The Wharton School, University of Pennsylvania.

Stoll, Hans R. 1978, The supply of dealer services in securities markets, The Journal of Finance 33, 1133-1151.

Taylor, John B., and John C. Williams, 2009, A Black Swan in the Money Market, American Economic Journal: Macroeconomics 1, 58-83.

Trebbi, Francesco, and Kariong Xiao, 2015, Regulation and market liquidity, Working Paper 2173, NBER.

Vayanos, Dimitri, and Jiang Wang, 2012, Liquidity and Asset Prices under Asymmetric Information and Imperfect Competition, The Review of Financial Studies 25, 1339-1365.

Vayanos, Dimitri, and Pierre-Olivier Weill, 2008, A Search-Based theory of the on-the-run phenomenon, The Journal of Finance, 63, 1351-1389.

Weill, Pierre-Olivier, 2007, Leaning against the wind, The Review of Economic Studies 74, 1329-1354.

White, Halbert, 1980, A Heteroskedasticity-Consistent Covariance Matrix Estimator and a Direct Test for Heteroskedasticity, Econometrica 48, 817-38. 


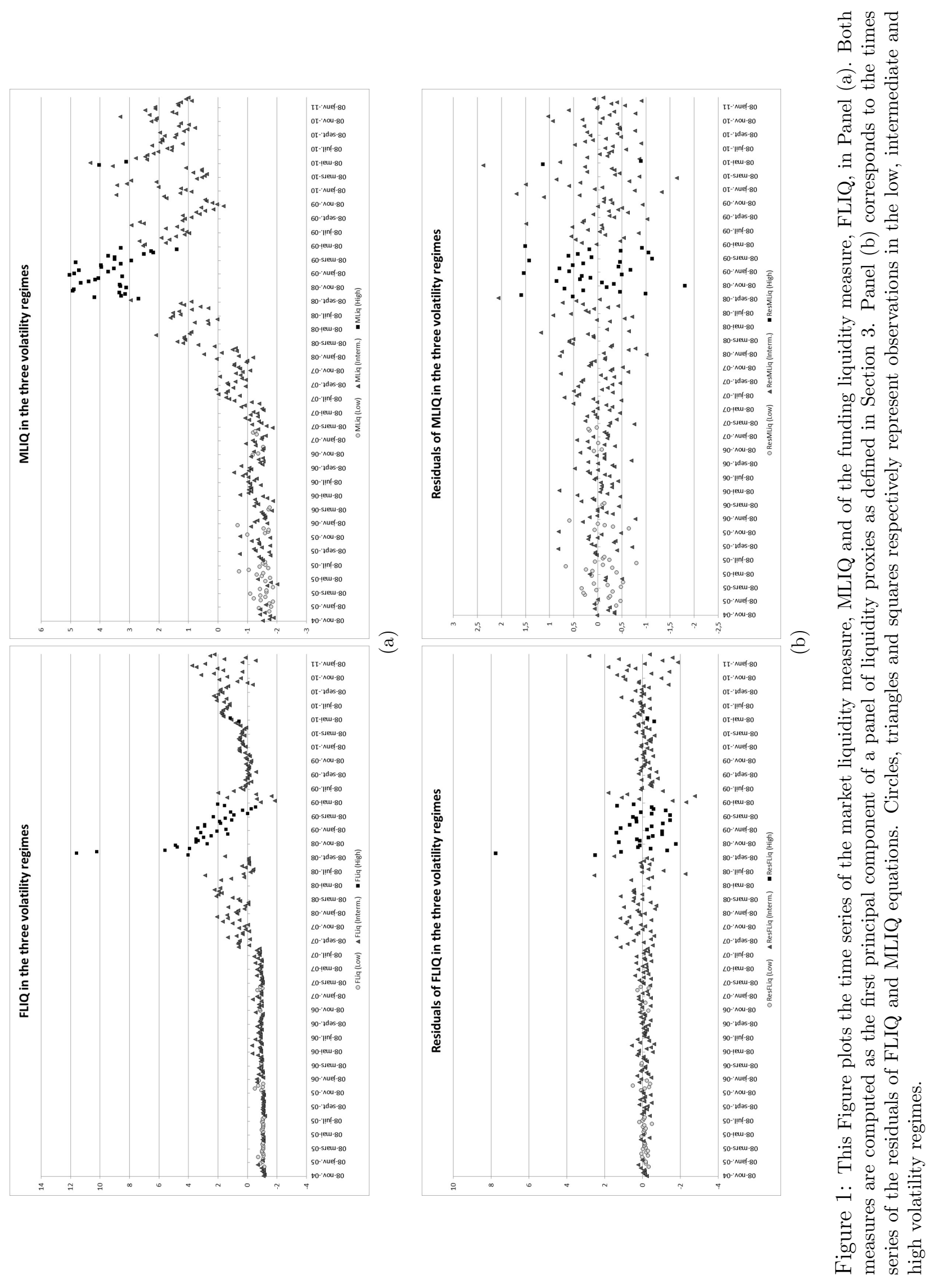




\section{Table 1: Descriptive statistics}

The table reports the average statistics for the ten Euro-area government bond markets. We only consider fixed-rate coupon bonds with maturity between one year and thirty years, issued by the central government and traded on the MTS platform from Oct 1, 2004 to Feb 28, 2011. We focus on the bonds that are traded at least 15 days in each of the 3 volatility regimes. Panel (a) reports the country average statistics, and Panel (b) reports statistics on the cross-section of bonds. In the tables, No. denotes the total number of bonds for each country, Yield is the end-of-day miquote bond yield (in percentage), YTM is the years to maturity (in years), Duration is the bond duration (in years), Coupon is the coupon rate (in \%), is the number of market makers over the whole sample period, Trades is the average weekly number of transactions per bond over the whole sample period and Size is the average trade size in mio euros over the whole period. In Panel (b), we additionally report statistics on the bond's Haircut, the number of Market Makers, the CDS of the bond, a proxy for Flight to Quality defined as the coefficient of the bond's yield change regressed on the first difference of the average spread across the 5-year CDS contracts across countries (from Bloomberg), and a dummy $D_{F t o Q}$ that takes value one if Flight to Quality is negative, and zero otherwise.

\section{Statistics by country}

(a)

\begin{tabular}{lrrrrrrrr}
\hline Country & No. & Yield & YTM & Duration & Coupon & No. MM & Trades & Size \\
\hline Austria & 10 & 3.82 & 10.17 & $9.2 Y$ & 4.51 & 22 & 34 & 8.34 \\
Belgium & 12 & 3.71 & 10.32 & 9.12 & 4.72 & 29 & 124 & 8.25 \\
Finland & 4 & 3.38 & 6.29 & 7.23 & 4.90 & 29 & 143 & 9.47 \\
France & 29 & 3.52 & 9.80 & 7.01 & 4.80 & 24 & 133 & 7.06 \\
Germany & 23 & 3.27 & 9.73 & 8.7 & 4.32 & 20 & 146 & 6.66 \\
Greece & 14 & 4.11 & 7.81 & 7.49 & 5.15 & 27 & 132 & 7.58 \\
Italy & 29 & 3.97 & 11.21 & 7.44 & 2.44 & 51 & 1,219 & 5.67 \\
Netherlands & 11 & 3.50 & 11.01 & 8.91 & 4.74 & 28 & 40 & 9.02 \\
Portugal & 5 & 3.80 & 7.03 & 7.58 & 4.27 & 23 & 70 & 9.09 \\
Spain & 12 & 3.73 & 8.46 & 8.03 & 4.76 & 29 & 92 & 8.74 \\
\hline
\end{tabular}

\section{Cross-sectional statistics}

(b)

\begin{tabular}{lrrrrr} 
& Mean & Median & Std & Min & Max \\
\hline No. & & \multicolumn{1}{c}{149} \\
Yield & 3.68 & 3.90 & 0.93 & 0.12 & 6.18 \\
YTM & 9.25 & 7.23 & 6.64 & 2.86 & 28.41 \\
Duration & 8.41 & 8.14 & 2.98 & 2.74 & 16.92 \\
Coupon & 4.11 & 4.00 & 1.36 & 1.38 & 8.50 \\
Part. & 27 & 23 & 15 & 8 & 76 \\
Trades & 20 & 8 & 37 & 0 & 562 \\
Size & 7.11 & 7.00 & 3.23 & 0.50 & 230.50 \\
Haircut & 3.44 & 3.00 & 2.22 & 0.50 & 10.50 \\
CDS & 27.65 & 21.12 & 18.11 & 4.82 & 89.67 \\
Flight to quality & -0.06 & -0.04 & 0.11 & -1.11 & 0.04 \\
$D_{F t o Q}$ & 0.93 & 1 & 0.26 & 0 & 1 \\
\hline & & & & & \\
\hline
\end{tabular}




\section{Table 2: Statistics of market liquidity}

The table reports the summary statistics of market liquidity variables across European Treasury bond markets. We only consider fixed-rate coupon bonds with maturity between one year and thirty years, issued by the central government and traded on the MTS platform from Oct 1, 2004 to Feb 28, 2011. Market liquidity variables include the the effective spread (EBAS, in bp), bid-ask spread (BAS, in bp), price-impact (IMP) and Amihud's ILLIQ measure. The definition of all measures is discussed in Section 3. The market liquidity variables are equal-weighted averages across all bonds and markets on a weekly basis. Panel (a) reports the country average statistics (the mean and the standard deviation in parenthesis), and Panel (b) reports the mean, median, standard deviation, min and max of the cross-section of individual bonds. Panel (c) reports the correlations between the four market liquidity measures.

\section{Descriptive statistics of market liquidity variables by country}

(a)

\begin{tabular}{lllll}
\hline & \multicolumn{4}{c}{ Market Liquidity Measure } \\
\hline Country & EBAS & BAS & ILLIQ & IMP \\
\hline Austria & $4.65(4.54)$ & $8.52(5.20)$ & $2.14(1.58)$ & $0.79(1.45)$ \\
Belgium & $3.89(3.52)$ & $7.32(4.61)$ & $1.78(1.22)$ & $0.61(0.87)$ \\
Finland & $3.03(3.39)$ & $6.08(4.79)$ & $1.17(1.07)$ & $0.50(0.92)$ \\
France & $3.24(2.19)$ & $7.37(3.43)$ & $2.38(1.25)$ & $0.70(0.98)$ \\
Germany & $2.42(1.12)$ & $5.88(2.06)$ & $1.61(1.03)$ & $0.97(1.44)$ \\
Greece & $3.87(4.72)$ & $6.53(4.62)$ & $1.74(1.55)$ & $1.30(2.58)$ \\
Italy & $3.50(2.97)$ & $7.14(4.31)$ & $1.40(0.82)$ & $0.64(0.65)$ \\
Netherlands & $2.97(2.03)$ & $6.77(3.14)$ & $1.67(0.72)$ & $0.46(0.46)$ \\
Portugal & $4.50(6.78)$ & $6.90(5.45)$ & $1.25(1.69)$ & $0.68(1.56)$ \\
Spain & $4.42(4.61)$ & $7.55(5.12)$ & $1.74(1.26)$ & $0.67(0.93)$ \\
\hline
\end{tabular}

\section{Cross-sectional statistics of market liquidity variables}

(b)

\begin{tabular}{lrrrr}
\hline \multicolumn{5}{c}{ Market Liquidity Measure } \\
\hline Panel & EBAS & BAS & ILLIQ & IMP \\
\hline Mean & 3.74 & 7.90 & 1.92 & 0.72 \\
Median & 2.07 & 4.53 & 1.79 & 0.42 \\
Std Dev & 2.92 & 4.73 & 0.69 & 0.70 \\
Min & 1.02 & 3.19 & 0.77 & 0.21 \\
Max & 11.32 & 16.08 & 4.46 & 3.80 \\
AC $(1)$ & 0.95 & 0.96 & 0.69 & 0.86 \\
\hline
\end{tabular}

Correlations of market liquidity measures

(c)

\begin{tabular}{lrrrr}
\hline \multicolumn{5}{c}{ Market Liquidity Measure } \\
\hline Variables & EBAS & BAS & ILLIQ & Impact \\
\hline EBAS & 1 & 0.92 & 0.66 & 0.85 \\
BAS & & 1 & 0.64 & 0.75 \\
ILLIQ & & & 1 & 0.63 \\
Impact & & & & 1 \\
\hline
\end{tabular}




\section{Table 3: Statistics of funding liquidity}

Panel (a) reports the summary statistics of European funding liquidity variables from Oct 1, 2004 to Feb 28, 2011. Funding liquidity variables include the spreads (in basis points) between Euribor, General Collateral Repo, the ECB's Main-Refinancing Operation Rates over the overnight-index-swap (OIS) rate or the Euribor, and the $\mathrm{Hu}$, Pan and Wang (2013) measure of noise. The definition of all measures is discussed in Section 3. The funding liquidity variables are equal-weighted averages across markets on a weekly basis. Mean, Std, Min, Max denote the average, standard deviation, minimum and maximum of the variables. AC(1) denotes the first-order autocorrelation coefficients of the variables. Panel (b) reports the correlations between the five funding liquidity measures.

\section{Descriptive statistics on Funding Liquidity measures}

(a)

\begin{tabular}{lrrrr}
\hline \multicolumn{5}{c}{ Funding Liquidity Measure } \\
\hline & Euribor & Repo & MRO & Noise \\
\hline Mean & 6.07 & 6.36 & 18.16 & 0.19 \\
Median & 2.80 & 3.20 & 2.15 & 0.03 \\
Std Dev & 9.92 & 9.34 & 26.00 & 0.22 \\
Min & -17.00 & -7.50 & -8.50 & 0.03 \\
Max & 98.90 & 85.00 & 111.00 & 1.02 \\
AC(1) & 0.75 & 0.86 & 0.94 & 0.92 \\
\hline
\end{tabular}

\section{Correlations of funding liquidity measures}

(b)

Funding Liquidity Measures

\begin{tabular}{lrrrr}
\hline Variables & Euribor & Repo & MRO & Noise \\
\hline Euribor & 1 & 0.94 & 0.24 & 0.14 \\
Repo & & 1 & 0.29 & 0.28 \\
MRO & & & 1 & 0.64 \\
Noise & & & & 1 \\
\hline
\end{tabular}




\section{Table 4: Principal Component Analysis}

Panel (a) reports the results from the principal component analysis of funding and market illiquidity variables. FLIQ is the first principal component of the changes in the four funding liquidity variables. MLIQ denotes the first principal component of the changes in the four market liquidity variables. Panel (b) reports the factor weights in the PCA decomposition. Panel (c) reports the correlations of the FLIQ and MLIQ measures with the standard liquidity measures defined in Section 3.

\section{Principal component analysis of funding and market liquidity variables}

(a)

\begin{tabular}{rrrrrrr}
\hline & \multicolumn{2}{c}{ Funding Liquidity Measures } & \multicolumn{3}{c}{ Market Liquidity Measures } \\
& Eigenvalue & Proportion & Cumulative & Eigenvalue & Proportion & Cumulative \\
\hline PC1 & 2.28 & 0.57 & 0.57 & 3.25 & 0.81 & 0.81 \\
PC2 & 1.30 & 0.33 & 0.90 & 0.44 & 0.11 & 0.92 \\
PC3 & 0.36 & 0.09 & 0.99 & 0.26 & 0.06 & 0.99 \\
\hline
\end{tabular}

Principal component analysis - Factor weights

(b)

\begin{tabular}{lrrrrrrrr}
\hline & \multicolumn{4}{c}{ Funding Liquidity Measures } & \multicolumn{3}{c}{ Market Liquidity Measures } \\
& Euribor & Repo & MRO & Noise & EBAS & BAS & Impact & ILLIQ \\
\hline PC1 & 0.55 & 0.59 & 0.43 & 0.40 & 0.53 & 0.51 & 0.50 & 0.45 \\
PC2 & -0.46 & -0.37 & 0.54 & 0.60 & -0.28 & -0.26 & -0.22 & 0.89 \\
PC3 & -0.07 & 0.13 & -0.72 & 0.68 & -0.15 & -0.60 & 0.79 & -0.02 \\
\hline
\end{tabular}

Contemporaneous Correlation Coefficients Across Liquidity Measures

(c)

\begin{tabular}{lllllllll}
\hline & \multicolumn{3}{c}{ Funding Liquidity Measures } & \multicolumn{5}{c}{ Market Liquidity Measures } \\
Correlation & Euribor & Repo & MRO & Noise & EBAS & BAS & Impact & ILLIQ \\
\hline FLIQ & 0.84 & 0.88 & 0.65 & 0.60 & & & & \\
MLIQ & & & & & 0.96 & 0.93 & 0.90 & 0.80 \\
\hline
\end{tabular}




\section{Table 5: Volatility regimes}

Panel (a) reports the results from the White and the Breusch-Pagan heteroskedasticity test for funding and market illiquidity variables over the sample period from Oct 1, 2004 to Feb 28, 2011. The first two columns correspond to funding and market illiquidity defined as the principal component of a panel of empirical proxies. FLIQ is the first principal component of the changes in the four funding liquidity variables. MLIQ denotes the first principal component of the changes in the four market liquidity variables. The last two columns corresponds to measures of funding illiquidity and market illiquidity as respectively the Euribor-OIS spread and the effective bid-ask spread. From the vStoxx index, we classify three volatility regimes. Panel (b) reports the variances and covariances of the innovations in the market and funding illiquidity measures in the three regimes, for the systematic components and the single measures. p-values are obtained from bootstrap with 1,000 replications. ${ }^{* * *}$ indicates that coefficients are significantly different from zero at the $1 \%$ level.

\section{Tests for Heteroskedasticity}

(a)

\begin{tabular}{crrrr}
\hline Variables & FLIQ & MLIQ & Euribor & EBAS \\
\hline White Statistic & 19.91 & 34.52 & 11.94 & 24.33 \\
Breusch-Pagan Statistic & 18.64 & 35.37 & 11.20 & 22.98 \\
\hline
\end{tabular}

\section{Variance-Covariance of the innovations under different regimes}

(b)

\begin{tabular}{lrrr}
\hline Variables & Low vStoxx & Interm. vStoxx & High vStoxx \\
\hline & & & \\
Variance of $\epsilon_{M L I Q}$ & 0.09 & 0.26 & 0.70 \\
Variance of $\epsilon_{F L I Q}$ & 0.03 & 0.38 & 2.68 \\
Covariance $\epsilon_{M L I Q}, \epsilon_{F L I Q}$ & 0.01 & 0.03 & 0.33 \\
& & & \\
Variance of $\epsilon_{E B A S}$ & 0.055 & 0.137 & 0.344 \\
Variance of $\epsilon_{E U R I B O R}$ & 0.028 & 0.311 & 2.104 \\
Covariance $\epsilon_{E B A S}, \epsilon_{E U R I B O R}$ & 0.002 & 0.004 & 0.153 \\
& & & \\
No. of obs. & 40 & 250 & 35 \\
Freq. of obs. & $12.31 \%$ & $76.92 \%$ & $10.77 \%$ \\
\hline
\end{tabular}




\section{Table 6: Heteroskedasticity identification}

The table shows the coefficients and the t-values (in parentheses) of the parameters of the structural model based on Rigobon (2003). The first two columns correspond to funding and market illiquidity defined as the principal component of a panel of empirical proxies. FLIQ is the first principal component of the changes in the four funding liquidity variables. MLIQ denotes the first principal component of the changes in the four market liquidity variables. The last two columns corresponds to measures of funding illiquidity and market illiquidity as respectively the Euribor-OIS spread and the effective bid-ask spread. p-values are obtained from bootstrap with 1,000 replications. ${ }^{* * *}$ indicates that coefficients are significantly different from zero at the $1 \%$ level.

\begin{tabular}{lrrrr}
\hline & \multicolumn{2}{c}{ First Principal Components } & \multicolumn{2}{c}{ Direct proxies } \\
\hline & MLIQ & FLIQ & \multicolumn{1}{c}{ EBAS } & Euribor-OIS \\
\hline$\beta$ (funding to market) & $0.151^{* * *}$ & & $0.120^{* * *}$ & \\
& $(57.12)$ & & $(53.90)$ & \\
$\alpha$ (market to funding) & & $0.080^{* * *}$ & & $0.033^{* * *}$ \\
& & $(28.47)$ & & $(16.88)$ \\
Implied volatility (vStoxx) & $0.016^{* * *}$ & 0.008 & $0.009^{* * *}$ & -0.002 \\
& $(4.14)$ & $(0.13)$ & $(4.33)$ & $(-0.46)$ \\
Variation in M2 money supply & $-0.220^{* * *}$ & -0.013 & $-0.131^{* * *}$ & 0.018 \\
& $(-4.06)$ & $(-0.28)$ & $(-4.06)$ & $(0.34)$ \\
Mutual funds' flows & $-0.380^{* * *}$ & 0.081 & $-0.012^{*}$ & 0.005 \\
& $(-2.55)$ & $(0.29)$ & $(-1.86)$ & $(0.36)$ \\
End-of-month dummy & -0.023 & $0.250^{* * *}$ & 0.05 & $0.22^{* * *}$ \\
& $(-0.37)$ & $(2.38)$ & $(1.06)$ & $(2.44)$ \\
\hline
\end{tabular}




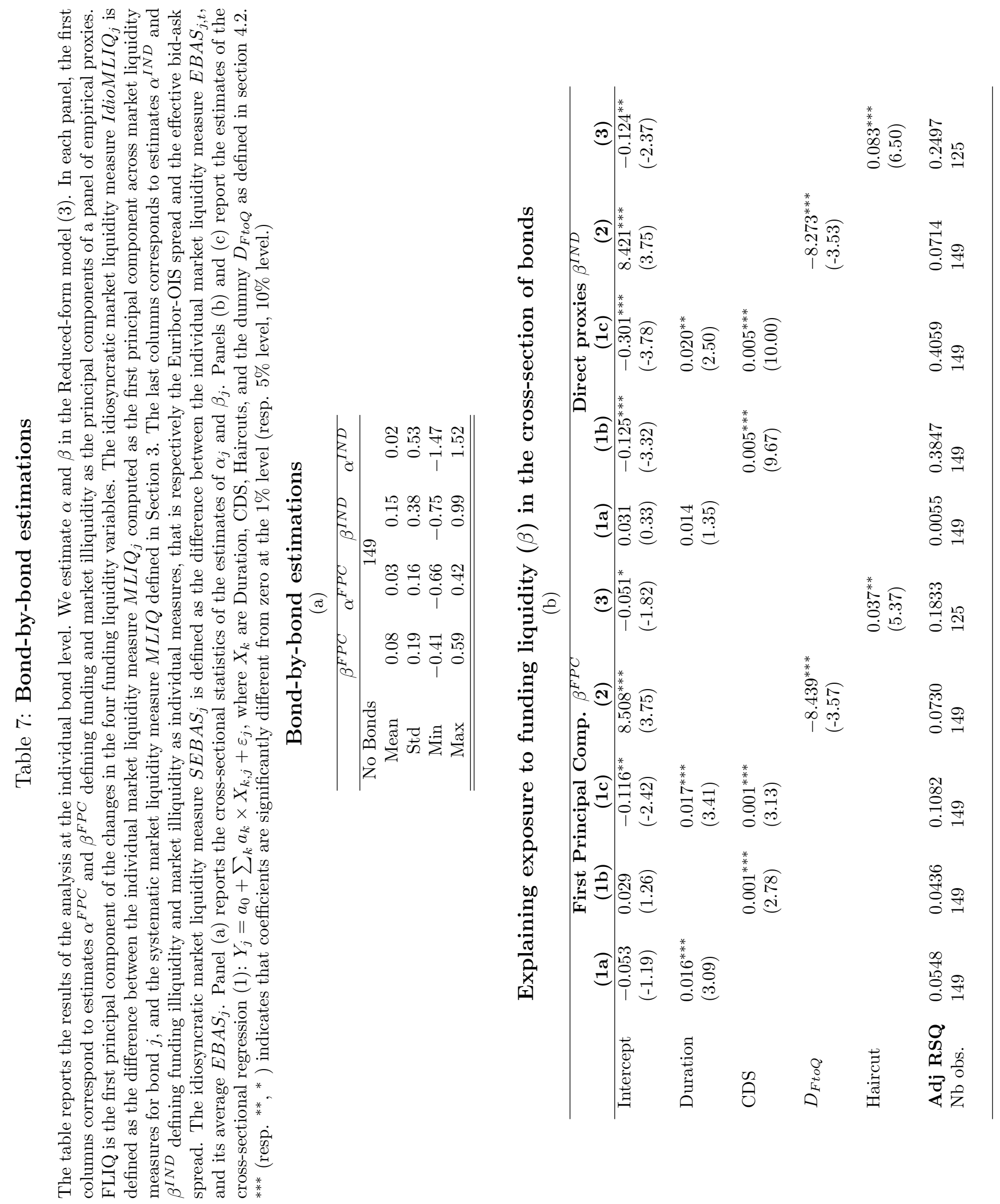




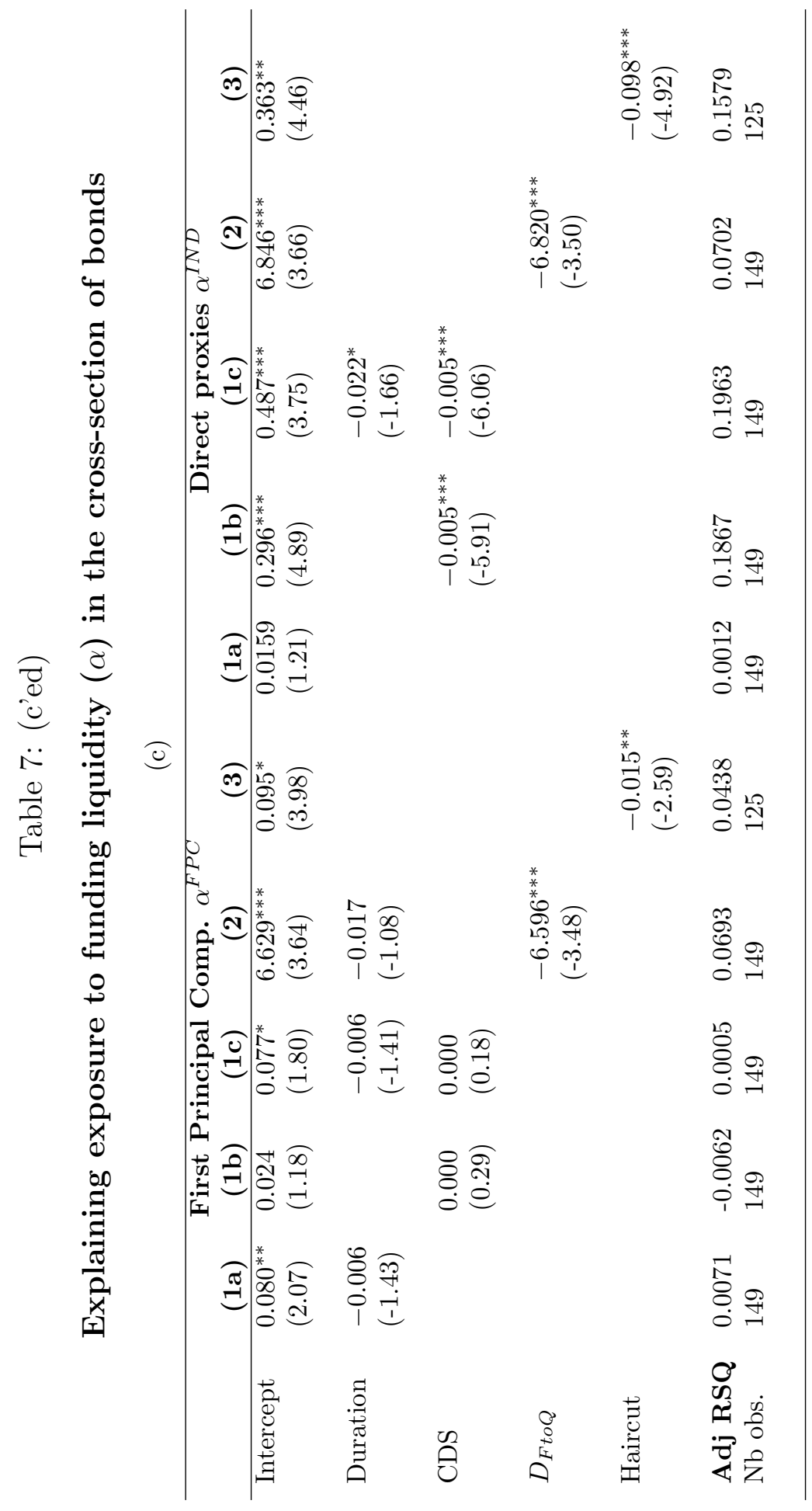




\section{Table 8: Robustness check: Full sample of bonds}

Panel (a) reports the country average statistics for the full sample of the ten Euro-area government bond markets. We consider all fixed-rate coupon bonds with maturity between one year and thirty years, issued by the central government and traded on the MTS platform from Oct 1, 2004 to Feb 28, 2011. No. denotes the total number of bonds for each country, Yield is the end-of-day miquote bond yield (in percentage), YTM is the years to maturity (in years), Duration is the bond duration (in years), Coupon is the coupon rate (in percentage), No. $M M$ is the number of market makers, Trades is the average weekly number of transactions per bond over the whole sample period and Size is the average trade size over the whole period. Panel (b) shows the coefficients and the t-values (in parentheses) of the parameters of the structural model based on Rigobon (2003), estimated on the full sample of bonds. The first two columns correspond to funding and market illiquidity defined as the principal component of a panel of empirical proxies. FLIQ is the first principal component of the changes in the four funding liquidity variables. MLIQ denotes the first principal component of the changes in the four market liquidity variables. The last two columns corresponds to measures of funding illiquidity and market illiquidity as respectively the Euribor-OIS spread and the effective bid-ask spread. p-values are obtained from bootstrap with 1,000 replications. ${ }^{* * *}$ indicates that coefficients are significantly different from zero at the $1 \%$ level.

\section{Statistics by country on the full sample of bonds}

(a)

\begin{tabular}{lrrrrrrrr}
\hline Country & No. & Yield & YTM & Duration & Coupon & No. MM & Trades & Size \\
\hline Austria & 19 & 3.65 & 10.83 & 7.84 & 4.63 & 28 & 61 & 4.46 \\
Belgium & 34 & 3.46 & 8.47 & 6.42 & 5.01 & 35 & 226 & 5.02 \\
Finland & 13 & 3.27 & 7.69 & 6.30 & 4.37 & 35 & 79 & 4.76 \\
France & 70 & 3.32 & 7.94 & 5.96 & 4.70 & 24 & 256 & 4.39 \\
Germany & 104 & 3.16 & 6.68 & 5.06 & 4.26 & 27 & 256 & 4.39 \\
Greece & 35 & 3.84 & 7.80 & 5.87 & 5.02 & 35 & 212 & 4.27 \\
Italy & 86 & 3.62 & 8.53 & 5.96 & 2.36 & 51 & 2,476 & 3.28 \\
Netherlands & 31 & 3.29 & 8.25 & 6.22 & 4.35 & 28 & 105 & 5.78 \\
Portugal & 21 & 3.65 & 9.20 & 7.02 & 4.50 & 37 & 215 & 4.89 \\
Spain & 39 & 3.56 & 8.70 & 6.40 & 4.65 & 37 & 187 & 4.88 \\
\hline
\end{tabular}

Heteroskedasticity identification on the full sample of bonds

(b)

\begin{tabular}{lrrrr}
\hline & \multicolumn{2}{c}{ First Principal Components } & \multicolumn{2}{c}{ Direct proxies } \\
\hline & MLIQ & FLIQ & \multicolumn{1}{c}{ EBAS } & Euribor-OIS \\
\hline$\beta$ (funding to market) & $0.063^{* * *}$ & & $0.070^{* * *}$ & \\
& $(5.18)$ & & $(20.83)$ & $0.055^{* * *}$ \\
$\alpha$ (market to funding) & & $0.052^{* * *}$ & & $(3.16)$ \\
& & $(32.64)$ & & 0.064 \\
Implied volatility (vStoxx) & $0.021^{* * *}$ & 0.008 & $0.033^{* * *}$ & $(1.16)$ \\
& $(3.99)$ & $(1.17)$ & $(5.25)$ & 0.070 \\
Variation in M2 money supply & $-0.050^{* * *}$ & -0.130 & $-0.151^{* * *}$ & $(0.18)$ \\
& $(-1.86)$ & $(-1.92)$ & $(-3.69)$ & -0.465 \\
Mutual funds' flows & $-0.160^{* * *}$ & -0.023 & $-0.440^{*}$ & $(-0.19)$ \\
& $(-2.02)$ & $(-0.08)$ & $(-1.86)$ & $1.840^{* * *}$ \\
End-of-month dummy & 0.038 & $0.220^{* * *}$ & 1.270 & $(2.39)$ \\
\hline
\end{tabular}




\section{Table 9: Robustness check: before / during the financial crisis}

The table shows the coefficients and the t-values (in parentheses) of the parameters of the structural model based on Rigobon (2003). Panel (a) reports the results on the non-crisis period (from Oct 1, 2004 to Sept 30, 2008), while Panel (b) reports the results on the crisis period (from Oct 1, 2008 to Feb 28, 2011). The first two columns correspond to funding and market illiquidity defined as the principal component of a panel of empirical proxies. FLIQ is the first principal component of the changes in the four funding liquidity variables. MLIQ denotes the first principal component of the changes in the four market liquidity variables. The last two columns corresponds to measures of funding illiquidity and market illiquidity as respectively the Euribor-OIS spread and the effective bid-ask spread. p-values are obtained from bootstrap with 1,000 replications. ${ }^{* * *}$ indicates that coefficients are significantly different from zero at the $1 \%$ level.

Before the financial crisis (from Oct 1, 2004 to Sept 30, 2008)

(a)

\begin{tabular}{lrrrr}
\hline \hline & \multicolumn{2}{c}{ First Principal Components } & \multicolumn{2}{c}{ Direct proxies } \\
\hline & MLIQ & FLIQ & \multicolumn{1}{c}{ EBAS } & Euribor-OIS \\
\hline$\beta$ (funding to market) & $0.15^{* * *}$ & & $0.056^{* * *}$ & \\
& $(27.66)$ & $0.10^{* * *}$ & & \\
$\alpha$ (market to funding) & & $(35.61)$ & & $0.030^{* * *}$ \\
& & 0.01 & $0.008^{* * *}$ & $0.014^{* * *}$ \\
Implied volatility (vStoxx) & $0.02^{* * *}$ & $(0.11)$ & $(2.18)$ & $(2.32)$ \\
& $(3.06)$ & -0.06 & $-0.083^{* * *}$ & 0.064 \\
Variation in M2 money supply & $-0.18^{* * *}$ & $(-0.82)$ & $(-2.21)$ & $(-1.10)$ \\
& $(-2.61)$ & 0.00 & -0.002 & 0.003 \\
Mutual funds' flows & -0.00 & $(1.12)$ & $(-0.33)$ & $(1.22)$ \\
& $(-0.86)$ & $0.24^{* * *}$ & 0.022 & 0.054 \\
End-of-month dummy & -0.04 & $(2.76)$ & $(0.56)$ & $(0.88)$ \\
\hline
\end{tabular}

During the financial crisis (from Oct 1, 2008 to Feb 28, 2011)

(b)

\begin{tabular}{lrrrr}
\hline \hline & \multicolumn{2}{c}{ First Principal Components } & \multicolumn{2}{c}{ Direct proxies } \\
\hline & MLIQ & FLIQ & \multicolumn{1}{c}{ EBAS } & Euribor-OIS \\
\hline$\beta$ (funding to market) & $0.16^{* * *}$ & & $0.067^{* * *}$ & \\
& $(39.68)$ & & $(11.32)$ & \\
$\alpha$ (market to funding) & & $0.08^{* * *}$ & & 0.020 \\
& & $(13.48)$ & & $(1.62)$ \\
Implied volatility (vStoxx) & $0.02^{* * *}$ & 0.01 & $0.010^{* * *}$ & -0.009 \\
& $(2.93)$ & $(1.99)$ & $(1.98)$ & $(-1.34)$ \\
Variation in M2 money supply & 0.14 & $-0.57^{* * *}$ & -0.006 & 0.199 \\
& $(0.63)$ & $(-2.38)$ & $(-0.03)$ & $(0.85)$ \\
Mutual funds' flows & $-0.01^{* * *}$ & 0.00 & $-0.007^{* * *}$ & 0.001 \\
& $(-2.38)$ & $(0.12)$ & $(-2.03)$ & $(0.82)$ \\
End-of-month dummy & -0.00 & $0.27^{* * *}$ & 0.110 & $0.354^{* * *}$ \\
& $(0.02)$ & $(1.76)$ & $(0.88)$ & $(2.17)$ \\
\hline
\end{tabular}




\section{Table 10: Robustness check: Quantile regressions}

The table reports the p-values of the null-hypothesis $H_{0}: \phi_{m}=\phi_{q}$ computed by estimating quantile regressions. $\phi=\alpha, \beta$ as in equations (1) and (2) of the main text and $m, q$ are the median and q-percentile, respectively.

\begin{tabular}{|c|c|c|c|}
\hline \multicolumn{4}{|c|}{$\phi_{m}=\phi_{0.7} \quad \phi_{m}=$} \\
\hline \multicolumn{4}{|c|}{ First principal components } \\
\hline funding to market $(\beta)$ & 0.60 & 0.12 & 0.88 \\
\hline market to funding $(\alpha)$ & 0.99 & 0.93 & 0.75 \\
\hline \multicolumn{4}{|c|}{ Direct measures } \\
\hline funding to market $(\beta)$ & 0.85 & 0.14 & 0.46 \\
\hline market to funding $(\alpha)$ & 0.58 & 0.97 & 0.54 \\
\hline
\end{tabular}

\section{Table 11: Robustness check: Volatility regimes defined based on rolling-window variances}

In line with Rigobon and Sack (2003), we define the various regimes globally from the reduced-form residuals by computing rolling-window variances of 20 -week worth of observations for each variable. A high (low) volatility regime is assigned if the volatility of that variable is larger (smaller) than its average value plus the value of the average volatility times a coefficient $c=0.5$. The Table reports the results of the estimation of the reduced-form model a la Rigobon (2003) defined in (3), on the subsample of 149 bonds as well as on the full sample. Values in parenthesis denote the t-values obtained by bootstrapping with 1,000 replications. *** indicates that coefficients are significantly different from zero at the $1 \%$ level.

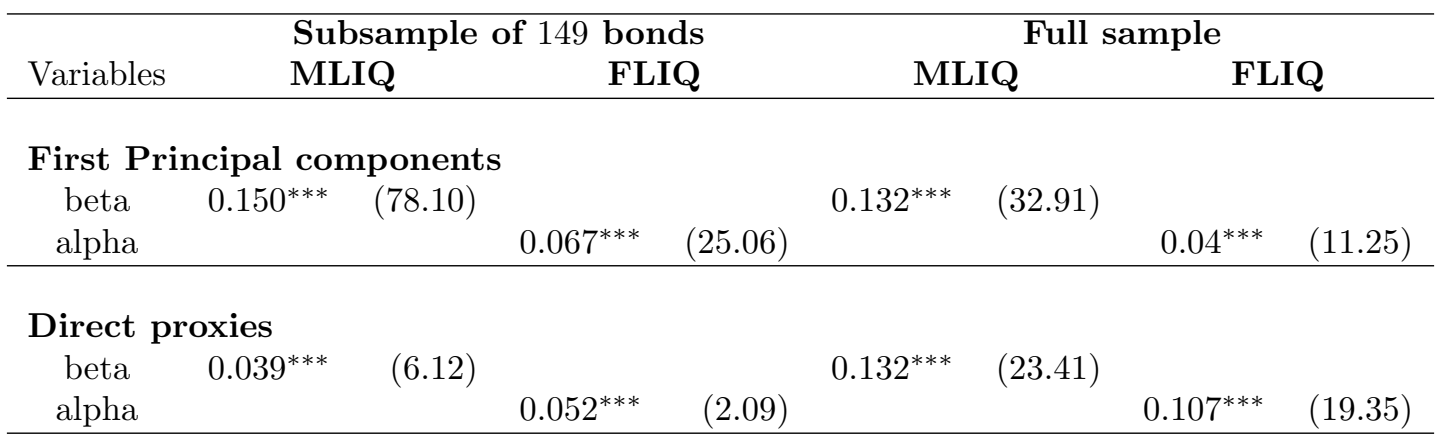




\section{Table 12: Robustness check: Rigobon and Sack (2003) identification}

The Table reports the estimates of an identification model based on Rigobon and Sack (2003). The model controls for an unobservable common shock, but prevents the complete characterisation of the alpha parameter. Instead, we obtain theta $=(1+$ alpha*gamma $) /($ beta+gamma $)$. Values in parenthesis denote the t-values obtained by bootstrapping with 1,000 replications. *** indicates that coefficients are significantly different from zero at the $1 \%$ level.

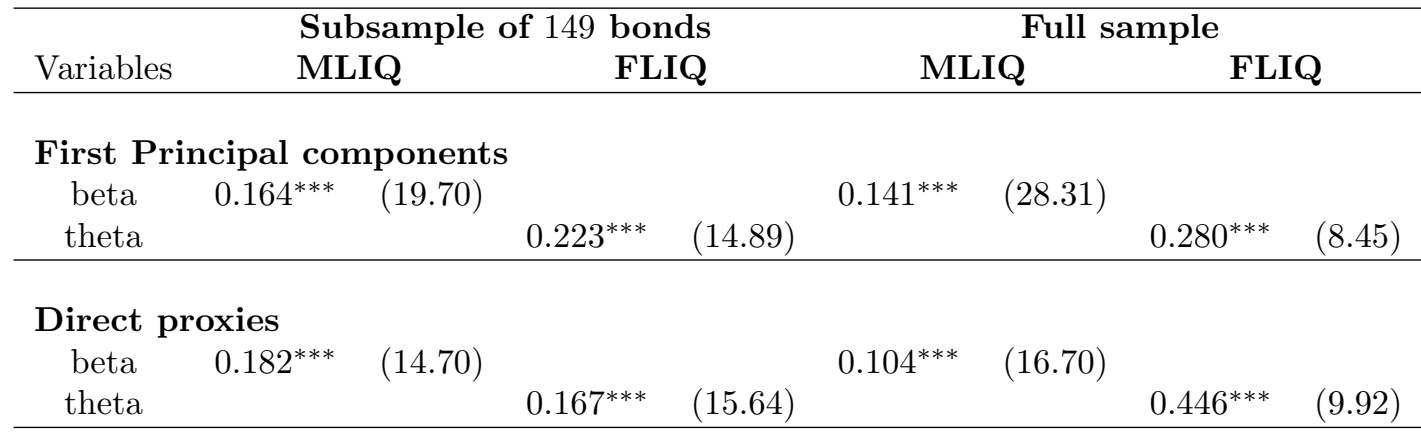

